\title{
Surficial weathering of iron sulfide mine tailings under semi-arid climate
}

\author{
Sarah M. Hayes ${ }^{\dagger}$, Robert A. Root, Nicolas Perdrial, Raina Maier, and Jon Chorover ${ }^{\star}$ \\ Department of Soil, Water and Environmental Science, University of Arizona, Tucson, AZ 85721
}

\section{Abstract}

Mine wastes introduce anthropogenic weathering profiles to the critical zone that often remain unvegetated for decades after mining cessation. As such, they are vulnerable to wind and water dispersion of particulate matter to adjacent ecosystems and residential communities. In sulfiderich ore tailings, propagation to depth of the oxidative weathering front controls the depthvariation in speciation of major and trace elements. Despite the prevalence of surficial mine waste deposits in arid regions of the globe, few prior studies have been conducted to resolve the nearsurface profile of sulfide ore tailings weathered under semi-arid climate. We investigated relations between gossan oxidative reaction-front propagation and the molecular speciation of iron and sulfur in tailings subjected to weathering under semi-arid climate at an EPA Superfund Site in semi-arid central Arizona (USA). Here we report a multi-method data set combining wet chemical and synchrotron-based X-ray diffraction (XRD) and X-ray absorption near-edge spectroscopy (XANES) methods to resolve the tight coupling of iron $(\mathrm{Fe})$ and sulfur $(\mathrm{S})$ geochemical changes in the top $2 \mathrm{~m}$ of tailings. Despite nearly invariant Fe and S concentration with depth (130-140 and 100-120 $\mathrm{g} \mathrm{kg}^{-1}$, respectively), a sharp redox gradient and distinct morphological change was observed within the top $0.5 \mathrm{~m}$, associated with a progressive oxidative alteration of ferrous sulfides to (oxyhydr)oxides and (hydroxy)sulfates. Transformation is nearly complete in surficial samples. Trends in molecular-scale alteration were co-located with a decrease in $\mathrm{pH}$ from 7.3 to 2.3, and shifts in Fe and S lability as measured via chemical extraction. Initial weathering products, ferrihydrite and gypsum, transform to schwertmannite, then jarosite-group minerals with an accompanying decrease in $\mathrm{pH}$. Interestingly, thermodynamically stable phases such as goethite and hematite were not detected in any samples, but ferrihydrite was observed even in the lowest pH samples, indicating its metastable persistence in these semiarid tailings. The resulting sharp geochemical speciation gradients in close proximity to the tailings surface have important

\footnotetext{
*Address correspondence to: Jon Chorover, Department of Soil, Water and Environmental Science, University of Arizona, $1177 \mathrm{E} 4^{\text {th }}$ St, Shantz 429, Tucson, AZ 85721. Telephone: +1 520-626-5635, Fax: 520-626-1647, chorover@ cals.arizona.edu.

†urrent address: Department of Chemistry \& Biochemistry, University of Alaska Fairbanks, Fairbanks, AK 99775-6160, s.hayes@alaska.edu

Robert Root: Department of Soil, Water and Environmental Science, University of Arizona, 1177 E $4^{\text {th }}$ St, Shantz 429, Tucson, AZ 85721 Telephone: +1 520-626-1307, Fax: 520-626-1647, robroot.az@gmial.com

Nicolas Perdrial: Department of Soil, Water and Environmental Science, University of Arizona, 1177 E $4^{\text {th }}$ St, Shantz 429, Tucson, AZ 85721 Telephone: +1 520-626-1566, Fax: 520-626-1647, perdrial@email.arizona.edu

Publisher's Disclaimer: This is a PDF file of an unedited manuscript that has been accepted for publication. As a service to our customers we are providing this early version of the manuscript. The manuscript will undergo copyediting, typesetting, and review of the resulting proof before it is published in its final citable form. Please note that during the production process errors may be discovered which could affect the content, and all legal disclaimers that apply to the journal pertain.
} 
implications for plant colonization, as well as mobility and bioavailability of co-associated toxic metal(loid)s.

\section{Keywords}

sulfur XANES; iron XANES; XAS; QXRD; semi-arid mine tailings

\section{INTRODUCTION}

Mine tailings, the fine-grained, uneconomical byproducts of ore processing (crushing, grinding, milling, and chemical leaching; Lottermoser, 2011) comprise the world's largest industrial waste stream (Hudson-Edwards et al., 2011). Mine waste deposition at the Earth's surface represents a massive annual production of fresh parent material for incipient soil formation whose rate is of similar magnitude to the naturally-occurring fresh rock reveal rate and the top soil loss rate (ca. $21 \mathrm{Gt} / \mathrm{yr}$; Wilkinson and McElroy, 2007; Lottermosser, 2010).

\subsection{Weathering of sulfide tailings}

Tailings weathering begins with the oxidative dissolution of pyrite-rich wastes and the release of sulfate $\left(\mathrm{SO}_{4}{ }^{2-}\right)$, metals $\left(\mathrm{Fe}^{2+}\right)$, and protons $\left(\mathrm{H}^{+}\right)$to solution (Nordstrom and Alpers, 1999). Production of $\mathrm{Fe}^{2+}$ and $\mathrm{H}^{+}$further promotes surface reaction and dissolution of pyrite and gangue (e.g., carbonate and silicate) minerals, and affects the geochemical (meta)stability of potential secondary phases (Blowes and Jambor, 1990; Blowes et al., 2003). Secondary phases may initially include $\mathrm{Fe}(\mathrm{II})$ and $\mathrm{Fe}(\mathrm{II} / \mathrm{III})$ sulfates such as melanterite $\left[\mathrm{FeSO}_{4}\right]$, copiapite $\left[\mathrm{Fe}^{\mathrm{II}} \mathrm{Fe}_{4}{ }_{4} \mathrm{II}\left(\mathrm{SO}_{4}\right)_{6}(\mathrm{OH})_{2} \cdot 22 \mathrm{H}_{2} \mathrm{O}\right]$, and coquimbite $\left.\left[\mathrm{Fe}_{2} \mathrm{SO}_{4}\right)_{3}\right]$, followed by ferric and mixed valent (hydr)oxides such as ferrihydrite $\left[5 \mathrm{Fe}_{2} \mathrm{O}_{3} \cdot 9 \mathrm{H}_{2} \mathrm{O}\right.$ ], goethite $[\mathrm{a}-\mathrm{FeO}(\mathrm{OH})]$, magnetite $\left[\mathrm{Fe}_{3} \mathrm{O}_{4}\right]$, green rust $\left[\mathrm{Fe}_{4}{ }^{\mathrm{II}} \mathrm{Fe}_{2}{ }^{\mathrm{III}}(\mathrm{OH})_{12} \mathrm{SO}_{4} \cdot \mathrm{nH}_{2} \mathrm{O}\right]$, schwertmannite $\left[\mathrm{Fe}_{8} \mathrm{O}_{8}(\mathrm{OH})_{6}\left(\mathrm{SO}_{4}\right) \cdot 10 \mathrm{H}_{2} \mathrm{O}\right]$, and jarosite $\left[\mathrm{KFe}_{3}(\mathrm{SO} 4)_{2}(\mathrm{OH})_{6}\right]$, listed in order of increasing stability with decreasing $\mathrm{pH}$ (Bigham et al., 1996; Bigham and Nordstrom, 2000; Jambor et al., 2000). Several studies have examined the gossan oxidative reaction front of sulfide tailings as a function of depth (Bigham et al., 1990; Blowes and Jambor, 1990; Dold and Fontboté, 2001; Dill et al., 2002; Jamieson et al., 2005; Romero et al., 2007; Schuwirth et al., 2007; Courtin-Nomade et al., 2009; Hayes et al., 2009; Jamieson, 2011; Hayes et al., 2012). In these studies, examination of the weathering profile as a function of depth lends insight into the sequence and stability of secondary phases in the weathering series.

Few studies, however, have examined tailings weathering profiles in arid and semi-arid environments. Low water through-flux and episodic wet-dry cycles in arid environments are expected to promote the persistence of (i) acidity and sulfate that would be leached with acid mine drainage (AMD) at higher pore volume hydrologic flux, and (ii) near-surface accumulation of minerals that would be soluble at higher relative humidity (HudsonEdwards et al., 1999). The few studies that have specifically examined mine tailings in (semi-)arid regions suggest that the weathering trajectory and (meta)stability of secondary species in these environments varies from the better studied humid environments (Wray, 
1998; Hudson-Edwards et al., 1999; Dold and Fontboté, 2001; Navarro et al., 2004; Hayes et al., 2009).

\subsection{Quantification of solid-phase speciation and element lability across the weathering front}

X-ray absorption near-edge structure (XANES) spectroscopy probes the bound-state electronic transitions of the absorbing atom and has been widely applied to quantify the oxidation state and coordination chemistry for both $\mathrm{Fe}$ and $\mathrm{S}$ in porous media (Myneni, 2002; Wetherall et al., 2008; Couture et al., 2010). Sulfur XANES (or S NEXAFS) enables quantification of sulfide and sulfate components in a mixture because the absorption peaks are spaced by $\sim 12 \mathrm{eV}$ across the -2 to +6 oxidation states (Fleet, 2005). Several excellent reviews on the application of S XANES to mineralogy and geochemistry represent the diversity of spectral structures deriving from distinct reference materials, many of which are directly relevant to metalliferous mine tailings (Myneni, 2000; Fleet, 2005). Sulfur XANES has been used to examine the S speciation of organic moieties in soils (e.g., Morra et al., 1997; Prietzel et al., 2003; Prietzel et al., 2009), sulfate species in aerosols (Takahashi et al., 2006), and S oxidation state in sediments (Neuhausler et al., 2003; Bostick et al., 2005), but it has not been extensively applied to study S speciation in mine tailings (Solis-Dominguez et al., 2012).

The first-derivative Fe XANES spectra of iron bearing phases have sufficiently unique spectral structure to differentiate between Fe containing mineral groups, e.g. phyllosilicates, carbonates, sulfides, oxides, sulfates, etc. (Waychunas et al., 1983; Combes et al., 1989;

Zhao et al., 1994; Manceau and Gates, 1997; O’Day et al., 2004). This information can be used to identify Fe species and monitor temporal and spatial redox changes in field and laboratory samples (Bajt et al., 1994; Zaw et al., 2002; Schmid et al., 2003; O'Day et al., 2004; Wilke et al., 2005; Root et al., 2007; Fittschen et al., 2008; Karlsson et al., 2008;

Marcus et al., 2008; Mitsunobu et al., 2008; Root et al., 2009).

Selective sequential extraction (SSE) of solids enables the quantification of lability of solidphase bound elements across a range of aqueous geochemical conditions (Williams et al., 1967; Tessier et al., 1979; Pickering, 1981; Dold and Fontboté, 2001, 2002; Dold, 2003b; Hayes et al., 2009). Although clearly operational (technique-dependent), results from SSEs are also quantitative and reproducible, with power to assess the changes in solid phase aqueous reactivity, particularly when applied across a well-characterized gradient in geochemistry, such as a reaction front. SSE is best utilized in conjunction with independent confirmation of solid phase speciation by, e.g., x-ray absorption spectroscopy or x-ray diffraction (Ruttenburg, 1992; La Force and Fendorf, 2000; Dold and Fontboté, 2002; Caraballo et al., 2009; Hayes et al., 2009). Indeed, coupling SSEs with complementary sample analysis methods is beneficial because of known potential artifacts including variable dissolution of both target and non-target phases, unintended precipitation of secondary phases, etc. (Kheboian and Bauer, 1987; Hayes et al., 2009).

The principal objective of the present study was to examine mineral transformation and speciation of major redox active elements, Fe and $\mathrm{S}$, across a gossan-type oxidative weathering front of sulfide-ore derived mine tailings in a semi-arid environment. Tailings 
were collected from a U.S. Environmental Protection Agency (EPA) Superfund site at the Iron King Mine and Humboldt Smelter Site (IKMHSS). The site was listed with the Comprehensive Environmental Response, Compensation, and Liability Act (CERCLA) in 2008 due to elevated levels of $\mathrm{Pb}$ and $\mathrm{As}\left(3.1\right.$ and $2.2 \mathrm{~g} \mathrm{~kg}^{-1}$, respectively in surficial tailings) and close proximity to residential communities. Geochemical interrogation of the near surface (top two meters) of the tailings was conducted with the goals of improving our basic understanding of oxidative sulfide weathering under semi-arid climate, facilitating assessment of potential health risks associated with such weathering, and providing a basis for remediation and prevention of off-site dispersion of metal-laden particles (SolisDominguez et al., 2012; Ramirez et al., 2013a; Ramirez et al., 2013b). Samples in this study were examined through the conjunctive use of wet chemical extractions and synchrotronbased mineralogical (XRD) and molecular-scale (Fe and S XANES) methods. Elucidation of dominant redox-active element behavior is key in addressing contaminant metal(loid) behavior, the subject of a current companion study.

\section{SITE DESCRIPTION}

Between 1906 and 1915, the IKMHSS (Dewey-Humboldt, Arizona, USA) was subject to mining of oxide ores of $\mathrm{Au}, \mathrm{Ag}$, and $\mathrm{Cu}$ (Creasey, 1952). Extraction began again during World War I to exploit the underlying massive sulfide deposit for base metals including $\mathrm{Cu}$, $\mathrm{Zn}$, and $\mathrm{Pb}$ and smaller amounts of precious metals Au and Ag (Fig. 1). During peak operation in 1950, daily ore processing was approximately 1,000 metric tons (Creasey, 1952; Myrick, 2001; Rayle et al., 2008). The principal mineral sources for $\mathrm{Cu}, \mathrm{Zn}$, and $\mathrm{Pb}$ were chalcopyrite $\left(\mathrm{CuFeS}_{2}\right)$, sphalerite $(\mathrm{ZnS})$, and galena $(\mathrm{PbS})$. The massive sulfide deposit was part of a mineral belt in steeply plunging echelon fine-grained veins of sulfides held together by a gangue of ankerite, quartz, sericite, and residual chlorite in the pre-cambrian metamorphosed andesitic tuffs that stretch tens of kilometers along the Bradshaw Mountain range in central AZ (USA; Creasey, 1952). From 1906-1947, Iron King produced 16,800 t $\mathrm{Pb}, 52,200 \mathrm{t} \mathrm{Zn}, 1800 \mathrm{t} \mathrm{Cu}, 105 \mathrm{t} \mathrm{Ag}$, and $3390 \mathrm{~kg} \mathrm{Au}$ from ca. 1 million metric tons of ore. Until mine closure in 1969, wastes were hydraulically sluiced, without compaction, into a small topographic depression covering approximately $620,000 \mathrm{~m}^{2}$ and piled to maximum of about $30 \mathrm{~m}$ thick, based on historical topographic maps (Fig. 1). It is estimated that four million cubic meters of tailings remain at the site.

During the half century since tailings deposition, mean annual precipitation and potential evapotranspiration at the $1400 \mathrm{~m}$ elevation IKMHSS site were ca. $370 \mathrm{~mm}$ and $1470 \mathrm{~mm}$, respectively. The IKMHSS tailings contain metal(loid) contaminants ( $\mathrm{As}, \mathrm{Pb}, \mathrm{Zn}$ ) above remediation limits and, meanwhile, tailings are subject to wind and water erosion into adjacent landscape locations, thereby increasing the environmental health risk to neighboring communities and ecosystems (Csavina et al., 2012; Ramierz et al., 2013a; Ramierz et al., 2013b). 


\section{MATERIALS AND METHODS}

\subsection{Field sampling, sample preservation, and reference material collection}

The IKMHSS tailings weathering profile was collected by excavating a pit to $c a .1 \mathrm{~m}$ to expose the redox boundary between oxic and sulfide-stable tailings. Samples were collected and composited across the pit faces for discrete depth intervals on the basis of morphological transitions (color, consistency, Fig 1B). A core extending to $2 \mathrm{~m}$ depth was extracted adjacent to the excavated pit to acquire deeper tailings (Fig. 1C). Samples were double bagged in sealed low $\mathrm{O}_{2}$ diffusion plastic bags and transported to the laboratory on dry ice $\left(-78^{\circ} \mathrm{C}\right)$. Pit and core samples were sub-sectioned in an anaerobic chamber (Coy, MI) to obtain three representative splits from each depth increment. Splits were (i) analyzed for moisture content and particle size; (ii) sieved $(<2 \mathrm{~mm})$, lyophilized at $-80^{\circ} \mathrm{C}$ and 130 mbar prior to chemical analysis; or (iii) kept field moist, frozen, and in darkness prior to sieving and grinding in preparation for XRD and XAS analysis. Petrographic analysis and $\mathrm{X}$-ray fluorescence maps were performed as described in the Electronic Annex (EA text, Fig. 1). Isolated grains, termed "as-collected," were visually distinguished and separated based on color and texture (Tan, Red, and Blue; Fig. 2).

Selected reference materials (ankerite, chlorite, gypsum, plumbojarosite, pyrite, and melanterite) were collected from mineral source distributors, whereas others (schwertmannite, 2-line ferrihydrite) were synthesized in accordance with published methods (Bigham et al., 1990; Regenspurg and Peiffer, 2005; Schwertmann and Cornell, 2000) (see Table EA-1 for details). All reagents used were ACS grade or better. The identities of all references were confirmed by XRD.

\subsection{Physical Analyses}

Wet and dry sediment color was determined using a Munsell soil color chart immediately after collection and also after preservation by freeze-drying. Particle size distributions for the $<2 \mathrm{~mm}$ size fractions were determined using a laser diffractometer (Beckman Coulter LS 13 320) in the University of Arizona Center for Environmental Physics and Mineralogy (Tucson, AZ) and quantified as clay $(<2 \mu \mathrm{m})$, silt $(2-50 \mu \mathrm{m})$ and sand $(50-2000 \mu \mathrm{m})$. Gravimetric water content was determined by weighing the tailings before and after drying at $105^{\circ} \mathrm{C}$ for $>24 \mathrm{~h}$.

\subsection{Chemical Analyses}

3.3.1 $\mathrm{pH}$ and electrical conductivity-Tailings $\mathrm{pH}$ was determined for replicate standardized slurries following reaction of $5.0 \mathrm{~g}$ of field moist tailings with $5.0 \mathrm{~mL}$ distilled deionized (DDI, $18.3 \mathrm{M} \Omega \mathrm{cm}$ ) water at $25^{\circ} \mathrm{C}$ for $1 \mathrm{~h}$ in an end-over-end rotator (McLean, 1982). After centrifugation and removal of supernatant, the $\mathrm{pH}$ of the supernatant was measured using a glass Ag-Ag electrode (Orion, epoxy semi-micro electrode) with twopoint calibration using standard buffer solutions and calibration checks at $\mathrm{pH} 4,7$ and 10.

3.3.2 Total metals-All tailings were analyzed for total elemental composition by inductively coupled plasma- optical emission spectroscopy (ICP-OES) and inductively coupled plasma- mass spectrometry (ICP-MS) following digestion or fusion. Copper, Zn, 
As, and $\mathrm{Pb}$ were measured by ICP-OES following total digestion ( $\left.\mathrm{HF}, \mathrm{HNO}_{3}, \mathrm{HClO}_{4}, \mathrm{HCl}\right)$, and all other elements reported by ICP-MS, following fusion with $\mathrm{LiBO}_{2}$ and $\mathrm{Li}_{2} \mathrm{~B}_{4} \mathrm{O}_{7}$ (Activation Labs, Ontario CA). Certified reference materials were digested and analyzed along with the tailings samples with an acceptance range of $\pm 10 \%$ of the certified value to verify precision and accuracy in sample preparation and analysis.

3.3.3 Selective Sequential Extraction (SSE)-A composite of the top $25 \mathrm{~cm}$ of tailings (material being used in remedial plant growth trials; Solis-Dominguez et al., 2012), as well as samples generated from discrete depth increments were subjected to a replicated six step SSE to quantify extractable solid phases, targeting soluble salts, adsorbed species, and poorly-crystalline as well as crystalline sulfate and oxide minerals (see Table 1 and detailed description in EA, modified after Dold (2003b and Neaman et al. (2004)). After the reaction time, suspensions were centrifuged and decanted and the supernatant was filtered ( $0.45 \mu \mathrm{m}$ nylon membrane filters) and acidified for preservation before analysis by ICP-MS. Between extraction steps, sediments were washed (washed with DDI water steps 1-4, and with HAc from 5-6), wash solution was analyzed for elemental composition with ICP-MS, and the concentration added to the relevant step. Averages are reported from extractions run in triplicate and compared to total concentrations from the ICP-MS/OES total digestion of a split sample as described above. An additional replicate was sacrificed and preserved after each step in the SSE for analysis by XRD and XAS.

\subsection{Spectroscopic Analyses}

3.4.1. X-ray Diffraction-For X-ray diffraction analysis, approximately $0.05 \mathrm{~g}$ of ground and homogenized sediments were packed between two layers of matte finish tape (Scotch Magic $^{\mathrm{TM}}$ ) to obtain a uniform thin layer sample. XRD data were collected at the Stanford Synchrotron Radiation Lightsource (SSRL) on beam line 11-3 operating at $\sim 12735 \mathrm{eV}(\lambda=$ $0.976 \AA$ ) in transmission mode with a focused spot size of $150 \mu \mathrm{m}$, using a $345 \mathrm{~mm}$ radius Mar detector image plate with a resolution of $100 \mu \mathrm{m}^{2}$ pixels, and calibrated to a $\mathrm{LaB}_{6}$ standard. Three scans were collected and summed for each sample. Laue pattern images were integrated into diffractograms using the Area Diffraction Machine software (Lande et al., 2007). The summed patterns were corrected for residual quartz saturation, systematic displacement and converted to conventional $\mathrm{Cu} \mathrm{Ka}$ wavelength. The background was manually subtracted and the contributions of amorphous phase(s) to the diffractograms were not included in the analysis. Quantitative phase analysis was performed using the Rietveld module included in the X'Pert HighScore Plus software (PANalytical) as described previously (Perdrial et al., 2011). All structural parameters for reference minerals were obtained from the American Mineralogist Crystal Structure Database (AMCSD) and the diffractograms were from the International Centre for Diffraction Data Powder Diffraction File (ICDD PDF-2) database (Downs and Hall-Wallace, 2003; ICDD, 2005).

\subsubsection{X-ray absorption spectroscopy}

Sulfur XANES: Sulfur XANES spectra were collected on beam lines 6-2 and 4-3 at the Stanford Synchrotron Radiation Lightsource (SSRL). All S XANES measurements were conducted within a helium atmosphere using an electron yield (EY) detector (to assess potential self-absorption and surface oxidation) or fluorescence detector (better S:N than 
EY), using a passivated implanted planar silicon (PIPS) detector. Energy calibration was performed between each set of sample scans using the maximum of the first peak of sodium thiosulfate, assigned to $2472.0 \mathrm{eV}$. Samples were prepared in a glove box (Coy, $95 \% \mathrm{~N}_{2}$, $5 \% \mathrm{H}_{2}$ gas mix) by applying a thin layer (ca. $5 \mu \mathrm{m}$ ) of sample on sulfur-free Mylar tape with a thin polypropylene cover to reduce oxidation. Samples were transported to the beam line under anoxic conditions and placed directly into the He environment at room temperature. Scans were collected over an energy range of 2445 to $2575 \mathrm{eV}$.

All scans were processed (dead-time corrected, calibrated, and averaged) using the SIXPACK software package (Webb, 2005). Data were normalized and fit using linear combinations of reference minerals collected under similar conditions from 2465 to 2515 $\mathrm{eV}$. The number of reference spectra in the final fits was determined based on PCA analysis indicating that three components were adequate to reconstruct the dataset (not shown). Reference spectra for final fits were selected from a library of $c a$. 30 references (Table EA-1, Fig. EA-3) on the basis of visual inspection and statistical comparisons of iterative fitting of different combinations of reference spectra. Plumbojarosite (representing jarositegroup minerals), gypsum, and pyrite reference spectra consistently yielded the best fit statistics and their presence in the tailings was confirmed by other methods including XRD and Fe XANES. Errors are reported as $\chi^{2}$, a statistical indicator of fit goodness calculated from the sum of squared error divided by the degrees of freedom in the fit.

Iron XANES: Iron K-edge XANES data were collected on SSRL beam lines 11-2 and 4-1 with beam energy of $300 \mathrm{~mA}$, a 30-element Ge array detector on BL 11-2 and a 13-element Ge array detector on BL 4-1, and a Si (220) phi= 90 double-crystal monochromator with 2 $\mathrm{mm}$ vertical beam slits. Energy was calibrated with an Fe metal foil, with the energy of the inflection of the first-edge assigned to be $7112 \mathrm{eV}$. To limit beam damage, all data were recorded at 7-15 K using an Oxford LHe cryostat. Samples were ground and homogenized in an anaerobic chamber (Coy, MI), mounted field moist in Teflon plates, sealed with Kapton tape, transferred to the beam line under anoxic conditions, and placed in the cryostat $\mathrm{He}$ atmosphere. XAS data were acquired between 6860 and $7810 \mathrm{eV}(\mathrm{k}=13.5)$ using $0.35 \mathrm{eV}$ energy steps in the XANES region. Reference samples were collected in fluorescence and transmission mode using the same procedures as for the tailings samples. Data collection and analysis of Fe reference compounds are described in detail in O'Day et al. (2004).

All scans were energy calibrated, dead time corrected (fluorescence measurements only), and averaged using the SIXPACK software package (Webb, 2005). Spectra were then background subtracted and normalized to the edge-step with EXAFSPAK software package (George and Pickering, 2000). The first derivative of normalized Fe XANES spectra were fit using linear combinations in the DATIT module of EXAFSPAK, (fit range 7105-7150 eV). Spectra were iteratively fit by trial-and-error with 1 to 4 components from a reference library of $\sim 30$ spectra (model spectra in Fig. EA-4, Table EA-1). Fits were optimized by allowing small energy shifts $(<1.0 \mathrm{eV})$ while fitting the component describing most of the spectral features and minimizing energy shifts in subsequent fit component parameters. Goodness-of-fit is reported as a 99\% confidence limit (three times the estimated standard deviation) derived from the variance-covariance matrix in the DATFIT software (Pickering, 2001). The confidence limit is a measure of the precision of a varied parameter but not 
necessarily the accuracy of the fit, in that it does not account for appropriateness of reference spectra, data quality, or differences in data collection (Pickering, 2001). Accuracy of linear combination analysis was previously investigated by O'Day et al. (2004), where it was shown that fits were within $\pm 5 \%$ of the actual mole percentages using the edge region $7100-7150 \mathrm{eV}$; with a detection limit for minor constituents of $c a .5 \%$. Additional FeXANES analysis of SSE residuals is described in Electronic Annex (EA text and Fig. EA-5).

\section{RESULTS}

\subsection{Physical and chemical characteristics}

The deepest tailings sample collected (sample G, $180 \mathrm{~cm}$ ) was apparently similar to the material initially deposited at the site; it did not exhibit visual evidence of oxidative transformation (Table 2, Fig. EA-1) and is characterized by a dark gray color and circumneutral $\mathrm{pH}(\mathrm{pH}=7.3)$. All other tailings exhibit visual evidence of progressive oxidative weathering, including lower $\mathrm{pH}$ (6.3 to 2.3) (Table 2). The most notable indicator of changing redox conditions is the dramatic color change from dark yellowish brown to greenish gray between samples $\mathrm{D}$ and $\mathrm{E}$. The oxidized surface of the tailings profile (top $c a$. $25 \mathrm{~cm})$, i.e., the gossan zone, had an orange color, acidic $\mathrm{pH}(\mathrm{pH}=2.3)$, and higher clay content relative the lower portion (>ca. $25 \mathrm{~cm}$ ) of the profile (Table 2).

The mass concentrations of major elements $\mathrm{Fe}$ and $\mathrm{S}$ exhibit small variation with depth (Table 2), suggesting that mineralogical changes may occur locally in the profile with little translocation of Fe or S to depth or off site. However, to better constrain chemical depletion or enrichment profiles for $\mathrm{Fe}$ and $\mathrm{S}$ across the reaction front, elemental analyses were normalized to $\mathrm{Ti}$, which was expected to be relatively immobile in the redox transition zone. Enrichment $(+\tau)$ or depletion $(-\tau)$ of $S$ and $\mathrm{Fe}$ are plotted as a function of depth relative to the "parent material" (represented here by the $180 \mathrm{~cm}$ sample) through the reaction front (top $60 \mathrm{~cm}$ ) of the tailings profile using Eq. 1 (Brimhall and Dietrich, 1987):

$$
\tau_{T i, j}=\frac{C_{j, w}}{C_{j, p}} \times \frac{C_{T i, p}}{C_{T i, w}}-1 \quad \text { [Eq. 1] }
$$

where $\tau_{\mathrm{T} i, \mathrm{j}}$ represents the chemical depletion (if negative) or enrichment (if positive) of element $j$ (Fe or $\mathrm{S}$ ) with respect to $\mathrm{Ti}$ in the weathering zone $(w)$ as measured relative to parent material $(p)$, and $C$ represents solid phase mass concentration. The $\tau_{\mathrm{T}}$ values for $\mathrm{S}$ and $\mathrm{Fe}$ show similar trends with moderate depletion in the oxic gossan zone, -0.35 for $\mathrm{S}$ and -0.31 for Fe, and slight enrichment below the redox boundary (Fig. 2a).

\subsection{Sequential selective extractions (SSE)}

The results of the SSE from the top $25 \mathrm{~cm}$ composite sample (Table 3) reveal that watersoluble (including efflorescent) salts released during the initial step represented a significant mass fraction of $\mathrm{Ca}(35 \%)$ and a smaller proportion of total $\mathrm{Mg}(8 \%)$. A comparable mass fraction of water soluble Mn (13\%) indicates that a portion of the total Mn may be precipitated as $\mathrm{Mn}$ (II) salts. The second step $\left(\mathrm{NH}_{4} \mathrm{NO}_{3}\right)$, targeting exchangeable ions, liberated most of the total $\mathrm{Na}(72 \%)$ and the second largest pool of $\mathrm{Ca}(30 \%)$. Elemental mass fractions were low overall during the third (AAc) step (which should include any 
residual carbonates), the highest being for $\mathrm{Fe}$ (7\%). Large pools of $\mathrm{Fe}(24 \%)$ were solubilized during oxalate-promoted dissolution targeting poorly-crystalline $\mathrm{Fe}(\mathrm{III})$ and $\mathrm{Al}(\mathrm{III})$ bearing solids (step 5). Most of the remaining Fe (41\%) was removed during dissolution targeting Fe(III) oxides/sulfates by citrate bicarbonate dithionite (CBD). This reductive dissolution of more crystalline secondary Fe(III) [and $\mathrm{Mn}(\mathrm{IV})$ ] solids released the largest extractable fraction of K (17\%, presumably from jarosite), and the second largest fraction of Mn (10\%). The AAO and CBD steps are both known to dissolve jarosite-group minerals (Dold, 2003a). Overall, these results indicate the presence of a large mass fraction of secondary Fe-bearing phases, as well as of soluble salts, in the top of portion of the profile. Since none of the SSE steps target silicate or sulfide minerals, the large pool of "residual" Fe (31\%) was attributed dominantly to silicates and sulfides. Results of synchrotron analyses on selected solid phase residual samples are discussed below.

An identical SSE was conducted on the full set of depth-resolved samples to assess trends in iron fractionation and lability through the redox boundary (Fig. 2b). In the near surface 0-5 $\mathrm{cm}$ (sample A), the largest fraction of $\mathrm{Fe}(64 \%)$ is extracted in the CBD step, targeting crystalline pedogenic ferric oxides/sulfoxides, e.g. jarosites. The second largest pool of $\mathrm{Fe}$ (20\%) was solubilized in the AAO step targeting poorly crystalline ferric (hydr)oxides, e.g ferrihydrite. At 5-15 cm (sample B) the CBD-extractable fraction decreased to $38 \%$ and the AAO-extractable fraction increased to $26 \%$, and there was also a significant water extractable fraction (5.3\%). At 15-25 cm (sample C) the CBD extractable Fe was decreased further (7.4\%), while $25 \%$ of the total Fe was extractable in AAO. From $25 \mathrm{~cm}$ to the deepest samples $(180 \mathrm{~cm})$ there was a small pool of AAc extractable Fe, targeting carbonates (e.g. ankerite). Hence, there is a general increase in the ratio of CBD to AAO extractable Fe moving up from the redox boundary to the surface that follows the trend of decreasing pH. Small but significant mass fractions of AAO-extractable Fe persist below the visually apparent (from color) redox boundary. On the basis of spectroscopic and diffraction data presented below, we attribute this to dissolution of pyritic fine particulates and/or postsampling oxidation of pyrite and precipitation of AAO extractable ferric (oxyhydr)oxide phases either during the SSE or during sample storage. Samples were kept frozen, isolated from oxygen, and analyzed as soon as possible by X-ray techniques, and while all spectroscopic techniques were carried out with great care to minimize post sampling oxidation, the SSE scheme was conducted in the open laboratory and was not isolated from molecular oxygen during the procedures.

Extractable $\mathrm{S}$ was released principally by the de-ionized water step, targeting soluble salts e.g. efflorescent salts and gypsum (10-27\% through the sample depths, not shown). A smaller pool extracted by $\mathrm{NH}_{4} \mathrm{NO}_{3}$, targeting exchangeable ions, decreased with depth. Little $\mathrm{S}$ was solubilized with the AAO extraction step, indicating that $\mathrm{S}$ was not occluded into ferric (oxyhydr)oxides. Sulfur was not quantified in the CBD step due to high background $\mathrm{S}$ from dithionite, but based on the Fe SSE the remaining $\mathrm{S}$ is attributable to jarosite in the near surface and increasingly to pyrite with depth. 


\subsection{Bulk mineralogy}

Bragg reflections from XRD were refined to quantify several phases present in the tailings (Fig. 3, Table 4), including quartz, feldspars, clays, sulfides, sulfates, and carbonates. In respect to $\mathrm{Fe}$ and $\mathrm{S}$ weathering, pyrite, present in all samples, shows increasing depletion toward the surface, where jarosite-group minerals (e.g., plumbojarosite, hydronium jarosite, jarosite, and natrojarosite) and gypsum were found to accumulate (Fig. 3, Table 4). Carbonate phases, identified only at $>25 \mathrm{~cm}$ depth, where $\mathrm{pH}>6$ (samples $\mathrm{D}-\mathrm{G}$ ), were predominantly in the form of ankerite, with smaller quantities of siderite, whereas calcite was detected only in the deepest sample G.

\subsection{X-ray absorption spectroscopy}

Despite relatively constant total mass concentrations of Fe and $\mathrm{S}$ with depth (Table 2), sulfur XANES reveals a systematic depth-dependency in S-containing minerals that can be quantified using linear combination fits to pyrite, gypsum, and jarosite-group (modeled using plumbojarosite) references (Fig. 4, Table 5). Pyrite, present in all samples, increases in mass fraction with depth (from 11 to $95 \%$ of the total S). Gypsum, while present in all samples, has its maximum contribution to total S mass at intermediate depth (sample D) and it decreases in prevalence both with increasing depth and toward the surface. The prevalence of jarosites decreases with increasing depth from $68 \%$ of total $\mathrm{S}$ in sample $\mathrm{A}(0-5 \mathrm{~cm})$ to undetectable in sample $\mathrm{D}(25-35 \mathrm{~cm})$ and below.

Iron XANES data likewise indicate coherent depth-dependent trends in iron sulfide, carbonate, (oxyhydr)oxide, and (hydroxy)sulfate in the top meter of IKMHSS tailings (Fig. 5 , Table 6). Consistent with the S XANES and XRD, the prevalence of pyrite decreased from $71 \%$ at $180-183 \mathrm{~cm}$ to $2 \%$ at $0-5 \mathrm{~cm}$. Ankerite was only detected in samples with $\mathrm{pH}$ $\geq 5.5$ (sample D), with maximum relative abundance of $22 \%$ in sample F. The relative abundance of ankerite is $12 \%$ in the deepest sample, consistent with its presence as a secondary phase precipitating during initial post-depositional pyrite oxidation. Ferrihydrite was detected in all surficial samples (samples A-E) with a maximum abundance in sample B. Schwertmannite is detected only in sample $\mathrm{C}$ where the bulk $\mathrm{pH}$ is intermediate $(\mathrm{pH}=$ 3.7). Jarosite-group minerals are present in the surficial samples A and B with abundance increasing toward the ground surface along with decreasing $\mathrm{pH}$.

Detrital iron-bearing silicates, represented in the reference set by ripidolite (CCa-2), an Fe rich chlorite-group, 2:1 layer-type clay, with $\mathrm{Fe}\left(\mathrm{Fe}^{\mathrm{III}} / \mathrm{Fe}^{\mathrm{II}}=1.15\right.$; O'Day et al., 2004) in octahedral coordination, was present in all samples, with a relative abundance that generally increased with depth. The chlorite spectrum obtained from CCa-2 contains several distinct features that are unique among the reference minerals and was essential to obtaining good reconstructions of sample spectra, as-collected grains, and SSE solid phase residual materials.

Analysis of the XANES spectra of SSE solid residuals from the surface composite sample $(0-25 \mathrm{~cm})$ revealed little change in the Fe mineralogy through the $\mathrm{NaH}_{2} \mathrm{PO}_{4}$ extraction (steps 1-3) (Table 6). However, the AAO step effectively removed ferrihydrite and possibly some poorly-crystalline jarosite, whereas the CBD extraction removed the crystalline iron 
(hydroxy)sulfates. After the CBD step, the Fe spectrum was fit very well to 63\% pyrite and $36 \%$ chlorite, the latter being difficult to recognize without Fe XANES analysis of the SSE residuals (EA text and Fig. EA-5). The Fe XANES of as-collected grains isolated by color revealed discrete Fe phases and assemblages that were used to improve the XANES fits of the pit samples. The Fe XANES of the as-collected grains showed jarosite-group minerals and ferrihydrite dominated the signal for the "Tan" sample, schwertmannite and ferrihydrite dominated the "Red" sample, and ankerite, pyrite, and chlorite dominated the "Blue" sample (Table 6, Fig. EA-2).

\section{DISCUSSION}

The results of this study indicate that when subjected to the low water through-flux associated with semi-arid climatic forcing, weathering of sulfidic mine tailings can result in a steep reaction front in close $(<2 \mathrm{~m})$ proximity to the ground surface. According to mass concentration and mass balance considerations (Table 2, Fig. 2a), most of the original Fe and $\mathrm{S}$ deposited as pyritic tailings remains in place across the gossan oxidation front. However, element fractionation patterns (e.g., Fig. 2a-b, Table 3), mineralogical results (Fig. 3, Table 4) and XANES data (Fig. 4-5) indicate near complete species transformations within the top half meter after 50 years of incongruent dissolution in situ. The shallowness of the reaction front is reflected in a return to 'parent' composition within 2 meters of depth.

\subsection{Mineral weathering trajectory}

At near $2 \mathrm{~m}$ depth, the mineral assemblage containing sulfide, carbonate, and phyllosilicate (sample G) is likely the same as that initially deposited, as there is little evidence of postdepositional oxidation. In this shallow weathering profile, pyrite, the dominant sulfide mineral, was detected in all samples but became significantly depleted in surficial layers (Fig. 3, Table 4). Agreement between Fe and S XANES fit results for pyrite quantification using these two methods is demonstrated in Figure 6 by close agreement of the data (solid line, $r^{2}=0.944$ ) with the stoichiometric ratio Fe:2S expected for pyrite (dashed line). Slight overestimation by S XANES is consistent with the presence of smaller quantities of nonpyrite sulfide minerals in the tailings, particularly $\mathrm{ZnS}$ and $\mathrm{PbS}$, which were not included in the linear combination fits, and hence are not differentiated from the "pyrite" fraction assigned by $\mathrm{S}$ XANES.

Carbonate minerals, ankerite and siderite, were detected in small quantities at depth (samples D-G) by Q-XRD, Fe XANES and FT-IR (not shown). The assertion that the buffering capacity of these carbonate mineral fractions is consumed early in oxidative tailings diagenesis (Jambor et al., 2000) is supported in our data sets by (i) the sharply decreasing $\mathrm{pH}$ values (to below < 4) with distance from the redox boundary, (ii) progressive depletion of total carbonates detected in samples $\mathrm{G}$ to $\mathrm{D}$, and (iii) the apparent dissolution below detection of carbonates in tailings collected from shallow depths $(<25 \mathrm{~cm})$.

Important solid-phase products of sulfide weathering under semi-arid climatic forcing include gypsum that was observed at all depths using S XANES (5-60\%, with a maximum in sample D; Fig. 4, Table 5). The presence of gypsum in the deeper sulfide zone is likely due to lime-induced sulfide weathering during the initial milling process (Fig. 4, Table 5). 
The increase in its prevalence in the oxidized portion of the reaction front reflects not only greater degree of sulfur oxidation, but also insufficient water through-flux to remove from the profile soluble products of gypsum dissolution.

The diffuse redox boundary between sulfidic and oxidic tailings represents the penetration depth of reactive $\mathrm{O}_{2}$ diffusion and/or advection (via wetting front propagation) into the tailings. Prior studies demonstrate the rate of oxidation of sulfide-rich mine waste depends on the availability of $\mathrm{H}_{2} \mathrm{O}$, temperature, $\mathrm{Eh}, \mathrm{O}_{2}, \mathrm{Fe}^{3+}(a q)$, and particle size (e.g. Jambor et al., 2000; Blowes et al., 2003; Cai et al., 2009; Abrahams, 2012). The most obvious indication of the redox boundary in the IKMHSS tailings is the color change and the deepest occurrence of secondary $\mathrm{Fe}$ (hydr)oxides (sample E). The appearance of ferrihydrite at 38 $\mathrm{cm}$ depth (sample E; Fig. 5, Table 6), with a notable absence of jarosites and schwertmannite until $25 \mathrm{~cm}$ depth (sample C; Fig. 5, Table 6), suggests that ferrihydrite is the first metastable iron solid phase to form upon pyrite oxidation. Previous studies have reported the ubiquitous presence of ferrihydrite particularly in Fe- and S-rich mine-wastes at pH > 5.5-5.8 (Bigham et al., 1996; Williams et al., 2002). In an Eh-pH model of the IKMHSS tailings (Figure 7), we plot a range of $\log \mathrm{K}_{\mathrm{sp}}$ values for ferrihydrite (e.g. $\log \mathrm{K}_{\mathrm{sp}}$ $=3.0$ to 5.66; Delany and Lundeen, 1990; Majzlan et al., 2004), and suppress

thermodynamically-stable hematite, goethite, and magnetite to highlight the metastable iron phases observed. Evidently, the observation of ferrihydrite in samples E-A demonstrates its persistence far outside of its predicted stability field, down to $\mathrm{pH}=2.6$.

When water activity is assumed to equal one, iron (oxyhydr)oxide and (hydroxy)sulfate minerals are predicted to transform to goethite, a transformation generally thought to take months to years (Bigham et al., 1990; Murad and Rojik, 2005). Bigham (1996) reported the complete transformation of synthetic schwertmannite to goethite in 543 days. Interestingly, we see no evidence of such transformations in the IKMHSS tailings. The absence of XRD detectable crystalline goethite or hematite indicates that the transformation kinetics of ferrihydrite are retarded in this sulfate-rich, semi-arid environment. It is noteworthy, therefore, that no goethite or hematite has been detected at this site and metastable minerals appear to have persisted through $c a$. 50 years of weathering. Indeed, ferrihydrite persists at this site under much lower $\mathrm{pH}$ conditions than has previously been reported (e.g., $\mathrm{pH}=4.5-5$; Murad and Rojik, 2005).

Melanterite and schwertmannite were observed to occur exclusively in sample C (pH 3.7), signaling a metastable transition in the reaction front between ferrihydrite and jarosite.

Melanterite was detected by XRD but not Fe XANES, likely because of the heterogeneity of the natural samples. Schwertmannite is metastable at lower $\mathrm{pH}$ conditions than ferrihydrite (Fig. 7), and is most stable at pH 3-4 (Bigham et al., 1996). However, prior studies have reported the presence of schwertmannite in systems with pH 2.5 to 6.5 (Winland et al., 1991; Bigham et al., 1996; Murad and Rojik, 2005).

Jarosite-group minerals, along with ferrihydrite, were detected in samples A-B by XRD and XANES (both Fe and $\mathrm{S}$ ) and account for the principle secondary iron phases present at the tailings surface. Jarosites are most stable at low pH $(<2.8)$ conditions (Bigham et al., 1990; 
Bigham and Nordstrom, 2000; Murad and Rojik, 2005) and can contain a variety of cations, including protons, $\mathrm{H}_{3} \mathrm{O}^{+}, \mathrm{Na}^{+}, \mathrm{NH}_{4}^{+}$, and $\mathrm{Pb}^{2+}$ (Jambor et al., 2000).

Low water through-flux in (semi-)arid environments are expected to influence the rate and trajectory of mineral transformations and the formation and persistence of secondary phases (Jambor et al., 2000; Dill et al., 2002; Dill et al., 2012). Previous studies have reported the transformation of primary silicates, carbonates, and sulfides to secondary (oxyhydr)oxides and sulfate minerals under a range of climatic forcings (e.g., Hudson-Edwards et al., 1996; Murad and Rojik, 2005). Our results are generally consistent with previously reported results; we observe in the near-surface of the tailings profile (at the sub-meter scale) the incongruent weathering trajectory: pyrite, silicate minerals, and carbonates $\rightarrow$ ferrihydrite and gypsum $\rightarrow$ schwertmannite $\rightarrow$ jarosite-group minerals.

However, the mineralogical sequence observed at this site emphasizes the apparent persistence of metastable minerals, such as ferrihydrite and schwertmannite, at times under conditions far from their predicted equilibrium stability. The apparent persistence of these metastable phases may be largely due to (i) the retention against downward leaching of sulfate in tailings pore waters, since this inhibits the transformation of ferrihydrite to more crystalline phases (Majzlan and Myneni, 2005) and (ii) low relative humidity in semi-arid tailings (Majzlan, 2010). Hence, unlike mine tailings weathering processes in more humid environments, tailings diagenesis at IKHMSS is strongly controlled by low water activity and the fact that sulfate is not translocated to depth and out of the oxidative reaction front, a direct result of a semi-arid climate that imposes low pore volume through-flux.

\subsection{Depth of reaction front}

Clearest indication of the redox boundary in the IKMHSS tailings is the deepest occurrence of secondary $\mathrm{Fe}$ (hydr)oxides $(35-38 \mathrm{~cm}$ ) since this presents a distinctly orange color and dramatic change in mineralogy. However, evidence of oxidation in deeper samples is reflected in a decrease in $\mathrm{pH}$ and smaller percentage of calcite in sample $\mathrm{F}$ relative to sample $\mathrm{G}$, suggesting that penetration of oxygen to a depth of at least $55 \mathrm{~cm}$ may have resulted in the dissolution of calcite and the precipitation of small amounts of secondary carbonates, ankerite and siderite, not found in the materials upon deposition (sample G).

Although there are few prior studies that report depth of reaction front and oxidation in mine tailings, the IKMHSS tailings present a depth that is among the shallowest, particularly given the relatively long duration (> 50 years) of weathering. The best comparisons are perhaps porphyry $\mathrm{Cu}$ tailings piles in Chile (although those tailings had lower total sulfide content at $1-6 \%$ ) where oxidation was observed to a depth of 1.1 to $5 \mathrm{~m}$ depending on weathering time (20-40 years) and climate (alpine to hyper-arid; Dold and Fontboté, 2001). Reports from more temperate climates indicate a shallower penetration of $\mathrm{O}_{2}$ to a depth of $0.7 \mathrm{~m}$ in sulfide-rich tailings in Rhineland-Palatinate, Germany (Schuwirth et al., 2007) and 0.2-1.2 $\mathrm{m}$ in sub-humid Taxco tailings, located in south-central Mexico (Romero et al., 2007). Shallower reaction front depths in some more humid climates have been related to higher moisture content and sustained groundwater tables more proximal to the surface in moist climates, since slower diffusion of $\mathrm{O}_{2}$ occurs in water relative to air (Morth and Smith, 1996). Conversely, the shallow gossan front observed in the present study can be 
attributed to low water leaching that confines the weathering zone to the near surface, where it is potentially susceptible to erosive removal during extreme climatic events.

\section{CONCLUSIONS}

Whereas the production of acid mine drainage during water-tailings interaction is well documented, the mineralogical and geochemical trends recorded in the residual solid-phase weathering profile is less well known, particularly for arid systems. In this work, sulfide-ore derived tailings were collected across a weathering profile 50 years following deposition to assess how mineral transformation is coupled to major element (iron and sulfur) speciation change during oxidative weathering under semi-arid climate. Sharp gradients in mineral assemblage, iron and sulfur speciation, and element lability/fractionation were observed to occur at shallow depths $(<1 \mathrm{~m})$. Despite retention of both Fe and $\mathrm{S}$ in a system where potential evapotranspiration significantly exceeds precipitation on an annual basis, five decades of exposure to surficial conditions $\left(\mathrm{O}_{2}\right.$ and $\left.\mathrm{H}_{2} \mathrm{O}\right)$ has resulted in extensive mineral weathering in the top $0.5 \mathrm{~m}$, including the near complete depletion of sulfides in surficial layers and the formation of a coherent trend in complex secondary mineral assemblage and $\mathrm{pH}$ as a function of depth. Spatially-resolved sampling and analysis within the surface two meters indicates the reaction trajectory pyrite, silicate minerals and carbonates $\rightarrow$ ferrihydrite and gypsum $\rightarrow$ schwertmannite $\rightarrow$ jarosite-group minerals. Low water through-flux limits translocation of sulfate through the tailings profile and contributes to the persistence of metastable ferrihydrite and schwertmannite. The resulting shallow reaction front creates a gossan zone in the top $30 \mathrm{~cm}$ that is subject to potential off-site transport by wind and water erosion, which has important implications for contaminant dispersion, the subject of a companion study.

\section{Supplementary Material}

Refer to Web version on PubMed Central for supplementary material.

\section{Acknowledgments}

This research was supported by the National Institute of Environmental Health Sciences Grant numbers 2 P42 ES04940-11 and 1 R01ES017079-01. Portions of this research were carried out at the Stanford Synchrotron Radiation Laboratory, a National User Facility operated by Stanford University on behalf of the U.S. Department of Energy, Office of Basic Energy Sciences. The SSRL Structural Molecular Biology Program is supported by the Department of Energy, Office of Biological and Environmental Research, and by the National Institutes of Health, National Center for Research Resources, Biomedical Technology Program. We are grateful to Mary Kay Amistadi, Scott White, Corin Hammond, Xiaodong Gao, Peggy O’Day, Dorie Beals, and Robert Downs for assistance with sample analyses. The comments of AE Jan Wiederhold and three anonymous reviewers greatly helped to improve the earlier version of the manuscript.

\section{Abbreviations}

XAS X-ray Absorption Spectroscopy (both XANES and post edge regions)

XANES X-ray Absorption Near-Edge Spectroscopy

SSE Selective Sequential Extraction

Q-XRD Quantitative X-ray Diffraction 
IKMHSS Iron King Mine and Humbolt Smelter Superfund site

\section{References}

Abrahams PW. Involuntary soil ingestion and geophagia: A source and sink of mineral nutrients and potentially harmful elements to consumers of earth materials. Appl Geochem. 2012; 27:954-968.

Bajt S, Sutton SR, Delaney JS. X-ray microprobe analysis of iron oxidation states in silicates and oxides using X-ray absorption near edge structure (XANES). Geochim Cosmochim Acta. 1994; 58:5209-5214.

Bigham JM, Nordstrom DK. Iron and Aluminum Hydroxysulfates from Acid Sulfate Waters. Rev Mineral Geochem. 2000; 40:351-403.

Bigham JM, Schwertmann U, Carlson L, Murad E. A Poorly Crystallized Oxyhydroxysulfate of Iron Formed by Bacterial Oxidation of Fe(ii) in Acid-Mine Waters. Geochim Cosmochim Acta. 1990; 54:2743-2758.

Bigham JM, Schwertmann U, Traina SJ, Winland RL, Wolf M. Schwertmannite and the chemical modeling of iron in acid sulfate waters. Geochim Cosmochim Acta. 1996; 60:2111-2121.

Blowes DW, Jambor JL. The pore-water geochemistry and the mineralogy of the vadose zone of sulfide tailings, Waite Amulet, Quebec, Canada. Appl Geochem. 1990; 5:327-346.

Blowes, DW.; Ptacek, CJ.; Jambor, JL.; Weisener, CG. 9.05 - The Geochemistry of Acid Mine Drainage. In: Heinrich, DH.; Karl, KT., editors. Treatise on Geochemistry. Pergamon; Oxford: 2003. p. 149-204.

Bostick BC, Theissen KM, Dunbar RB, Vairavamurthy MA. Record of redox status in laminated sediments from Lake Titicaca: A sulfur K-edge X-ray absorption near edge structure (XANES) study. Chem Geol. 2005; 219:163-174.

Brimhall GH, Dietrich WE. Constitutive mass balance relations between chemical composition, volume, density, porosity, and strain in metosomatic hydrochemical systems: Results on weathering and pedogenesis. Geochim Cosmochim Acta. 1987; 51:567-587.

Cai Y, Pan Y, Xue J, Sun Q, Su G, Li X. Comparative XPS study between experimentally and naturally weathered pyrites. Appl Surf Sci. 2009; 255:8750-8760.

Caraballo MA, Rotting TS, Nieto JM, Ayora C. Sequential extraction and DXRD applicability to poorly crystalline $\mathrm{Fe}$ - and $\mathrm{Al}$-phase characterization from an acid mine water passive remediation system. Am Mineral. 2009; 94:1029-1038.

Combes JM, Manceau A, Calas G, Bottero JY. Formation of ferric oxides from aqueous-solutions - a polyhedral approach by x-ray absroption spectroscopy. 1 Hydrolysis and formation of ferric gels. Geochim Cosmochim Acta. 1989; 53:583-594.

Courtin-Nomade A, Grosbois C, Marcus MA, Fakra SC, Beny JM, Foster AL. The weathering of a sulfide orebody: speciation and fate of some potential contaminants. Can Mineral. 2009; 47:493508.

Couture RM, Gobeil C, Tessier A. Arsenic, iron and sulfur co-diagenesis in lake sediments. Geochim Cosmochim Acta. 2010; 74:1238-1255.

Creasey SC. Geology of the Iron King Mine, Yavapai County, Arizona. Econ Geol. 1952; 47:24-56.

Csavina J, Field J, Taylor MP, Gao S, Landázuri A, Betterton EA, Sáez AE. A review on the importance of metals and metalloids in atmosheric dust and aerosol from mining operations. Sci Total Environ. 2012; 433:58-73. [PubMed: 22766428]

Delany, JM.; Lundeen, SR. Reportt UCRL-21658. Lawrence Livermore National Laboratory; 1990. The LLNL Thermochemical Database.

Dill HG, Pöllmann H, Bosecker K, Hahn L, Mwiya S. Supergene mineralization in mining residues of the Matchless cupreous pyrite deposit (Namibia) - a clue to the origin of modern and fossil duricrusts in semiarid climates. J Geochem Explor. 2002; 75:43-70.

Dill HG, Weber B, Botz R. Metalliferous duricrusts - markers of weathering: A climatic and geomorphological approach to the origin of $\mathrm{Pb}-\mathrm{Zn}-\mathrm{Cu}-\mathrm{Sb}$-P-bearing chemical residues. J Geochem Explor. 2012; 112:123-195. 
Dold B. Dissolution kinetics of schwertmannite and ferrihydrite in oxidized mine samples and their detection by differential X-ray diffraction (DXRD). Appl Geochem. 2003a; 18:1531-1540.

Dold B. Speciation of the most soluble phases in a sequential extraction procedure adapted for geochemical studies of copper sulfide mine waste. J Geochem Explor. 2003b; 80:55-68.

Dold B, Fontboté L. Element cycling and secondary mineralogy in porphyry copper tailings as a function of climate, primary mineralogy, and mineral processing. J Geochem Explor. 2001; 74:355.

Dold B, Fontboté L. A mineralogical and geochemical study of element mobility in sulfide mine tailings of $\mathrm{Fe}$ oxide $\mathrm{Cu}-\mathrm{Au}$ deposits from the Punta del Cobre belt, northern Chile. Chem Geol. 2002; 189:135-163.

Downs RT, Hall-Wallace M. The American Mineralogist Crystal Structure Database. Am Mineral. 2003; 88:247-250.

Fittschen UEA, Meirer F, Streli C, Wobrauschek P, Thiele J, Falkenberg G, Pepponi G. Characterization of atmospheric aerosols using Synchroton radiation total reflection X-ray fluorescence and Fe K-edge total reflection X-ray fluorescence-X-ray absorption near-edge structure. Spectrochim Acta B. 2008; 63:1489-1495.

Fleet ME. XANES spectroscopy of sulfur in earth materials. Can Mineral. 2005; 43:1811-1838.

George, GN.; Pickering, IJ. EXAFSPAK: A suite of computer programs for analysis of X-ray absorption spectra. Stanford Synchrotron Radiation Laboratory; 2000.

Hayes SM, Webb SM, Bargar JR, O'Day PA, Maier RM, Chorover J. Geochemical Weathering Increases Lead Bioaccessibility in Semi-Arid Mine Tailings. Environ Sci Technol. 2012; 46:58345841. [PubMed: 22553941]

Hayes SM, White SA, Thompson TL, Maier RM, Chorover J. Changes in lead and zinc lability during weathering-induced acidification of desert mine tailings: Coupling chemical and micro-scale analyses. Appl Geochem. 2009; 24:2234-2245. [PubMed: 20161492]

Hudson-Edwards KA, Macklin MG, Curtis CD, Vaughan DJ. Processes of formation and distribution of $\mathrm{Pb}-, \mathrm{Zn}-, \mathrm{Cd}-$, and $\mathrm{Cu}$-bearing minerals in the Tyne Basin, northeast England: Implications for metal-contaminated river systems. Env Sci Technol. 1996; 30:72-80.

Hudson-Edwards KA, Schell C, Macklin MG. Mineralogy and geochemistry of alluvium contaminated by metal mining in the Rio Tinto area, southwest Spain. Appl Geochem. 1999; 14:1015-1030.

Hudson-Edwards KA, Jamieson HE, Lottermoser BG. Mine Wastes: Past, Present, Future. Elements. $2011 ; 7: 375-379$.

ICDD. JCPDS Powder Diffraction File 2 Database. International Centre for Diffraction Data. International Centre for Diffraction Data; Newton Square, PA, USA: 2005.

Jambor, JL.; Nordstrom, DK.; Alpers, CN.; Alpers, CN.; Jambor, JL.; Nordstrom, DK. Metal Sulfate Salts from Sulfide Mineral Oxidation. In: Ribbe, PH., editor. Sulfate Minerals- Crystallography, Geochemistry, and Environmental Significance. Mineralogical Society of America; Washinton DC, USA: 2000. p. 303-350.

Jamieson HE. Mine Wastes: Geochemistry and Mineralogy of Solid Mine Waste: Essential Knowledge for Predicting Environmental Impact. Elements. 2011; 7:381-386.

Jamieson HE, Robinson C, Alpers CN, Nordstrom DK, Poustovetov A, Lowers HA. The composition of coexisting jarosite-group minerals and water from the Richmond Mine, Iron Mountain, California. Can Mineral. 2005; 43:1225-1242.

Karlsson T, Persson P, Skyllberg U, Morth CM, Giesler R. Characterization of iron(III) in organic soils using extended X-ray absorption fine structure spectroscopy. Environ Sci Techol. 2008; 42:5449-5454.

Kheboian C, Bauer CF. Accuracy of selective extraction procedures for metal speciation in model aquatic sediments. Anal Chem. 1987; 59:1417-1423.

La Force MJ, Fendorf S. Solid-phase iron characterization during common selective sequential extractions. Soil Sci Soc Am J. 2000; 64:1608-1615.

Lande, J.; Webb, SM.; Mehta, A. Area Diffraction Machine. 2007. http://home.comcast.net/ $\sim$ sam_webb/adm.html

Lottermoser, BG. Mine Wastes: Characterization, Treatment and Environmental Impacts. SpringerVerlag; Berlin: 2010. 
Lottermoser BG. Recycling, Reuse and Rehabilitation of Mine Wastes. 2011; 7:405-410.

Majzlan J. Advances and gaps in the knowledge of thermodynamics and crystallography of acid mine drainage sulfate minerals. Chimia. 2010; 64:699-704. [PubMed: 21138157]

Majzlan J, Myneni SCB. Speciation of iron and sulfate in acid waters: Aqueous clusters to mineral precipitates. Environ Sci Techol. 2005; 39:188-194.

Majzlan J, Navrotsky A, Schwertmann U. Thermodynamics of iron oxides. III - Enthalpies of formation oand stability of ferrihydrite $(\mathrm{Fe}(\mathrm{OH}) 3)$, schwertmannite $(\mathrm{FeO}(\mathrm{OH}) 3 / 4(\mathrm{SO} 4) \mathrm{i} / 8)$, and Fe2O3. Geochim Cosmochim Acta. 2004; 68:1049-1059.

Manceau A, Gates WP. Surface structural model for ferrihydrite. Clay Clay Min. 1997; 45:448-460.

Marcus MA, Westphal AJ, Fakra SC. Classification of Fe-bearing species from Kedge XANES data using two-parameter correlation plots. J Synchrotron Radiat. 2008; 15:463-468. [PubMed: 18728317]

McLean, EO. Soil pH and lime requirement. In: Page, AL.; Miller, RH.; Keeney, DR., editors. Methods of soil analysis. Part 2. Chemical and microbiological properties. ASA and SSSA; Madison, WI: 1982.

Mitsunobu S, Sakai Y, Takahashi Y. Characterization of Fe(III) (hydr)oxides in arsenic contaminated soil under various redox conditions by XAFS and Mössbauer spectroscopies. Appl Geochem. 2008; 23:3236-3243.

Morra MJ, Fendorf SE, Brown PD. Speciation of sulfur in humic and fulvic acids using X-ray absorption near-edge structure (XANES) spectroscopy. Geochim Cosmochim Acta. 1997; 61:683688.

Morth AH, Smith EE. Kinetics of the sulfide-to-sulfate reaction. Am Chem Soc Div Fuel Chem. 1996; 10:83-92.

Murad E, Rojik P. Iron mineralogy of mine-drainage precipitates as environmental indicators: review of current concepts and a case study from the Sokolov Basin, Czech Republic. Clay Miner. 2005; 40:427-440.

Myneni, SCB. X-ray and vibrational spectroscopy of sulfate in earth materials. In: Alpers, CN.; Jambor, JL.; Nordstrom, DK., editors. Sulfate Minerals: Crystallography, Geochemistry, and Environmental Significance. Mineralogical Society of America; Washington DC: 2000. p. 113-172.

Myneni SCB. Soft X-ray spectroscopy and spectromicroscopy studies of organic molecules in the environment. Rev Mineral Geochem. 2002; 49:485-558.

Myrick, DF. Santa Fe to Phoenix. Railroads of Arizona. Signature Press; Berkeley, California: 2001.

Navarro A, Collado D, Carbonell M, Sanchez JA. Impact of mining activities on soils in a semi-arid environment: Sierra Almagrera district, SE Spain. Environ Geochem Hlth. 2004; 26:383-393.

Neaman A, Mouele F, Trolard F, Bourrie G. Improved methods for selective dissolution of Mn oxides: applications for studying trace element associations. Appl Geochem. 2004; 19:973-979.

Neuhausler U, Feng H, Jones KW. Characterization of sulfur in New York New Jersey waterway sediment. J Phys IV. 2003; 104:439-442.

Nordstrom, DK.; Alpers, CN. Geochemistry of acid mine waters. In: Plumlee, GS.; Logsdon, MJ., editors. Reviews in Economic Geology. The Environmental Geochemistry of Mineral Deposits. Part A. Processes, Methods and Health Issues. Soc. Econ. Geol; Littleton, CO: 1999. p. 133-160.

O’Day PA, Rivera N, Root R, Carroll SA. X-ray absorption spectroscopic study of Fe reference compounds for the analysis of natural sediments. Am Mineral. 2004; 89:572-585.

Perdrial N, Rivera N, Thompson A, O'Day PA, Chorover J. Trace contaminant concentration affects mineral transformation and pollutant fate in hydroxide-weathered Hanford sediments. J Hazard Mater. 2011; 197:119-127. [PubMed: 21993146]

Pickering, IJ. Edge Fitting Analysis using EXAFSPAK: A Tutorial. Stanford Synchrotron Radiation Laboratory; 2001.

Pickering WF. Selective chemical extractions of soil components and bound metal species. Crit Rev Anal Chem. 1981; 12:233-266.

Prietzel J, Thieme J, Neuhausler U, Susini J, Kogel-Knabner I. Speciation of sulphur in soils and soil particles by X-ray spectromicroscopy. Eur J Soil Sci. 2003; 54:423-433. 
Prietzel J, Thieme J, Tyufekchieva N, Paterson D, Mcnulty I, Kogel-Knabner I. Sulfur speciation in well-aerated and wetland soils in a forested catchment assessed by sulfur K-edge X-ray absorption near-edge spectroscopy (XANES). J Plant Nutr Soil Sci. 2009; 172:393-403.

Ramirez-Andreotta MD, Brusseau ML, Beamer P, Maier RM. Home gardening near a mining site in an arsenic-endemic region of Arizona: Assessing arsenic exposure dose and risk via ingestion of home garden vegetables, soils, and water. Sci Total Environ. 2013a; 454-455:373-382.

Ramirez-Andreotta MD, Brusseau ML, Artiola JF, Maier RM. A greenhouse and field-based study to determine the accumulation of arsenic in common homegrown vegetables grown in miningaffected soils. Sci Total Environ. 2013b; 443:299-306. [PubMed: 23201696]

Rayle, CE.; Solliday, S.; Vargas, VD. A cultural resource and historic building survey for a remedial investigation/feasibility study at the Iron King Mine-Humboldt Setler Superfund site, DeweyHumboldt, Yavapai Cpunty, Arizona. Environmental Protection Agency; 2008. EPW-06-004http://yosemite.epa.gov/r9/sfund/r9sfdocw.nsf/688299b284b16e92882574260073faef/ a5c1e8e6b65cce26882576fd0075b8ac!OpenDocument

Regenspurg S, Peiffer S. Arsenate and chromate incorporation in schwertmannite. Appl Geochem. 2005; 20:1226-1239.

Romero FM, Armienta MA, Gonzalez-Hernandez G. Solid-phase control on the mobility of potentially toxic elements in an abandoned lead/zinc mine tailings impoundment, Taxco, Mexico. Appl Geochem. 2007; 22:109-127.

Root RA, Dixit S, Campbell KM, Jew AD, Hering JG, O'Day PA. Arsenic sequestration by sorption processes in high-iron sediments. Geochim Cosmochim Acta. 2007; 71:5782-5803.

Root RA, Vlassopoulos D, Rivera NA, Rafferty MT, Andrews C, O’Day PA. Speciation and natural attenuation of arsenic and iron in a tidally influenced shallow aquifer. Geochim Cosmochim Acta. 2009; 73:5528-5553.

Ruttenburg KC. Development of a sequential extraction method for different forms of phosphorus in marine sediments. Limnol Oceanogr. 1992; 37:1460-1482.

Schmid R, Wilke M, Oberhänsli R, Janssens K, Falkenberg G, Franz L, Gaab A. Micro-XANES determination of ferric iron and its application in thermobarometry. Lithos. 2003; 70:381-392.

Schuwirth N, Voegelin A, Kretzschmar R, Hofmann T. Vertical distribution and speciation of trace metals in weathering flotation residues of a zinc/lead sulfide mine. J Environ Qual. 2007; 36:6169. [PubMed: 17215213]

Schwertmann, U.; Cornell, RM. Iron oxides in the laboratory: preparation and characterization. WileyVCH; Weinheim, NY: 2000.

Solis-Dominguez FA, White SA, Hutter TB, Amistadi MK, Root RA, Chorover J, Maier RM. Response of Key Soil Parameters during Compost-Assisted Phytostabilization in Extremely Acidic Tailings: Effect of Plant Species. Environ Sci Technol. 2012; 46:1019-1027. [PubMed: 22191663]

Takahashi Y, Kanai Y, Kamioka H, Ohta A, Maruyama H, Song Z, Shimizu H. Speciation of sulfate in size-fractionated aerosol particles using sulfur K-edge X-ray absorption near-edge structure. Environ Sci Technol. 2006; 40:5052-5057. [PubMed: 16955906]

Tessier A, Campbell PGC, Bisson M. Sequential extraction procedure for the speciation of particulate trace metals. Anal Chem. 1979; 51:844-851.

Waychunas G, Apted M, Brown G Jr. X-ray K-edge absorption spectra of Fe minerals and model compounds: Near-edge structure. Physics and Chemistry of Miner. 1983; 10:1-9.

Webb SM. Sixpack: A graphical user interface for XAS analysis using IFEFFIT. Phys Scr. 2005; T115:1011-1014.

Wetherall KM, Moss RM, Jones AM, Smith AD, Skinner T, Pickup DM, Goatham SW, Chadwick AV, Newport RJ. Sulfur and iron speciation in recently recovered timbers of the Mary Rose revealed via X-ray absorption spectroscopy. J Archaeol Sci. 2008; 35:1317-1328.

Wilke M, Partzsch GM, Bernhardt R, Lattard D. Determination of the iron oxidation state in basaltic glasses using XANES at the K-edge. Chem Geol. 2005; 220:143-161.

Wilkinson BH, McElroy BJ. The impact of humans on continental erosion and sedimentation. Geol Soc Am Bull. 2007; 119:140-156. 
Williams DJ, Bigham JM, Cravotta CA, Traina SJ, Anderson JE, Lyon JG. Assessing mine drainage $\mathrm{pH}$ from the color and spectral reflectance of chemical precipitates. Appl Geochem. 2002; 17:1273-1286.

Williams JD, Syers JK, Walker TW. Fractionation of soil inorganic phosphate by a modification of Chang and Jackson's procedure. Soil Sci Soc Am J. 1967; 31:736-739.

Winland RL, Traina SJ, Bigham JM. Chemical composition of ochreous precipitates from Ohio coal mine drainage. J Environ Qual. 1991; 20:452-460.

Wray DS. The impact of unconfined mine tailings and anthropogenic pollution on a semi-arid environment- an initial study of the Rodalquilar mining district, south east Spain. Environ Geochem Hlth. 1998; 20:29-38.

Zaw M, Szymczak R, Twining J. Application of synchrotron radiation technique to analysis of environmental samples. Nucl Instrum Meth B. 2002; 190:856-859.

Zhao JM, Huggins FE, Feng Z, Huffman GP. Ferrihydrite - Surface-structure and its effects on phase transformation. Clays Clay Min. 1994; 42:737-746. 


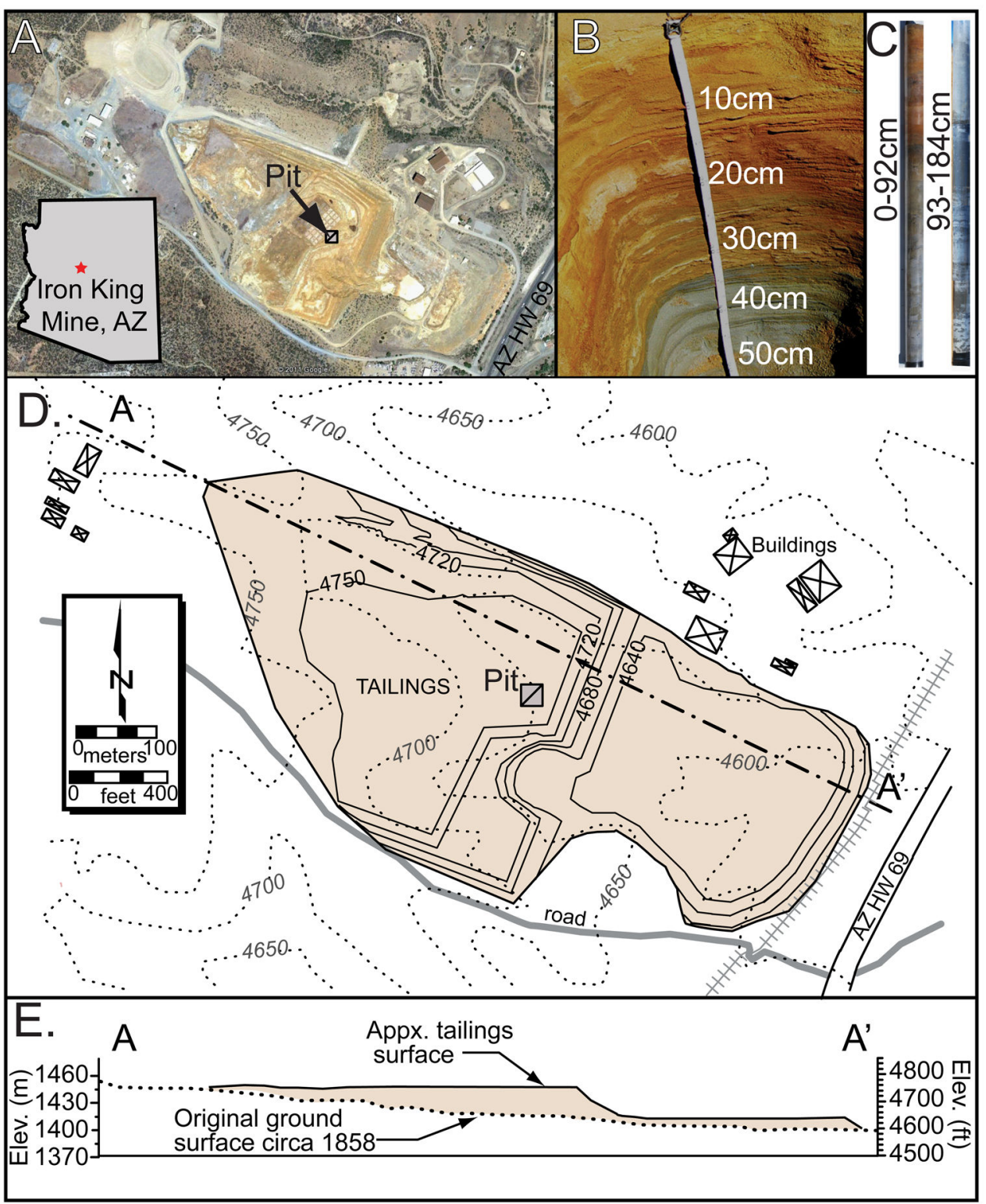

Figure 1.

Map and cross-section of Iron King Superfund site (Dewy-Humbolt, AZ). A) Aerial view of tailings pile (from Google Earth ${ }^{\mathrm{TM}}$ ), B) pit to $55 \mathrm{~cm}, \mathrm{C}$ ) cores to $185 \mathrm{~cm}, \mathrm{D}$ ) site map and E) cross section of waste pile containing ca. $3.9 \mathrm{Mm}^{3}$ of tailings. 


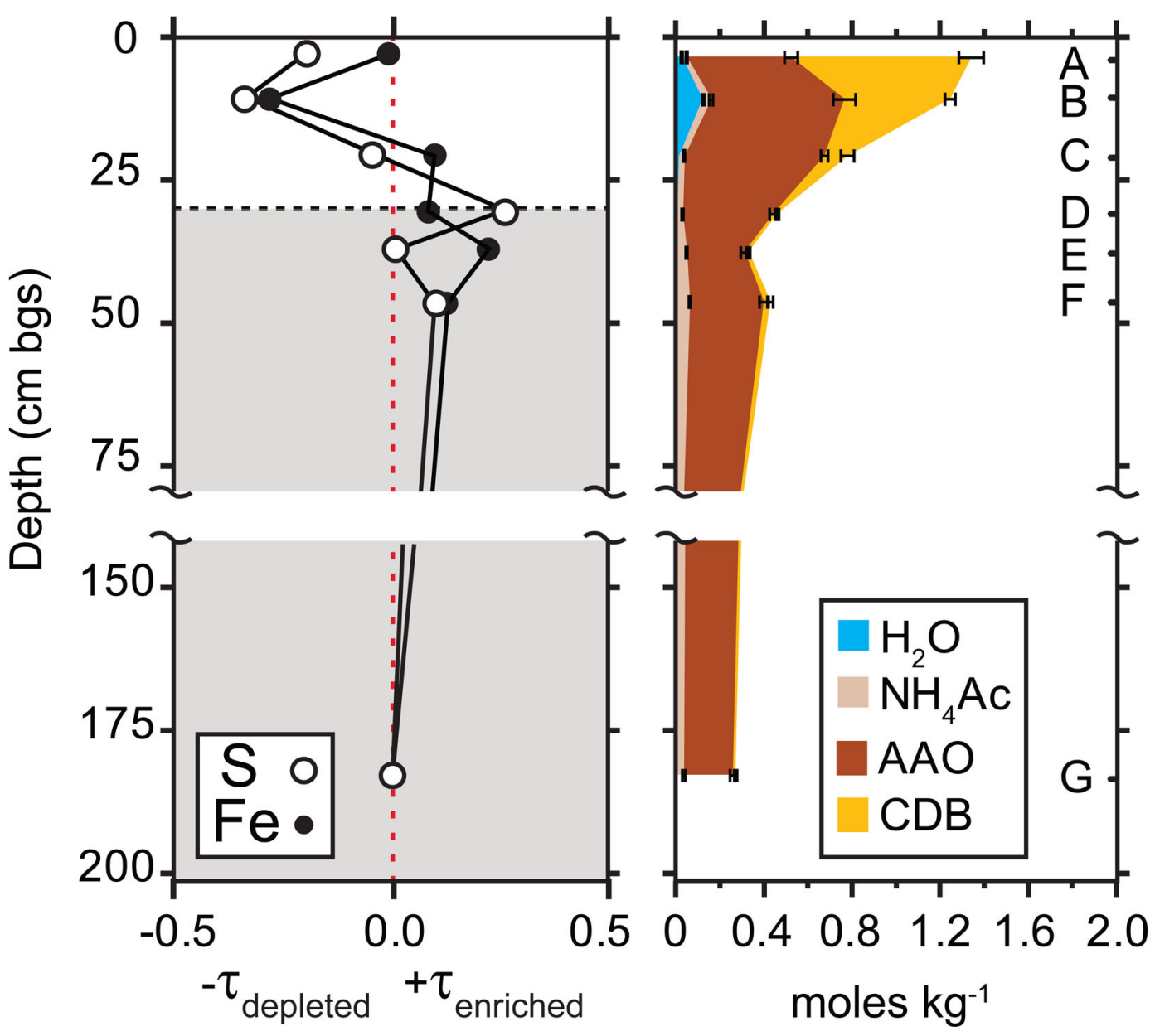

Figure 2.

(a) Chemical depletion/enrichment plot showing Ti normalized S (open) and Fe (closed) mass concentrations in the weathering profile relative to parent material taken as $180 \mathrm{~cm}$ sample (see Eq. 1), the dashed line and shaded regions represent the redox boundary. (b) Sequential extraction results for iron as a function of depth with error bars representing standard deviation of triplicate measurements (see online version for color coding). 


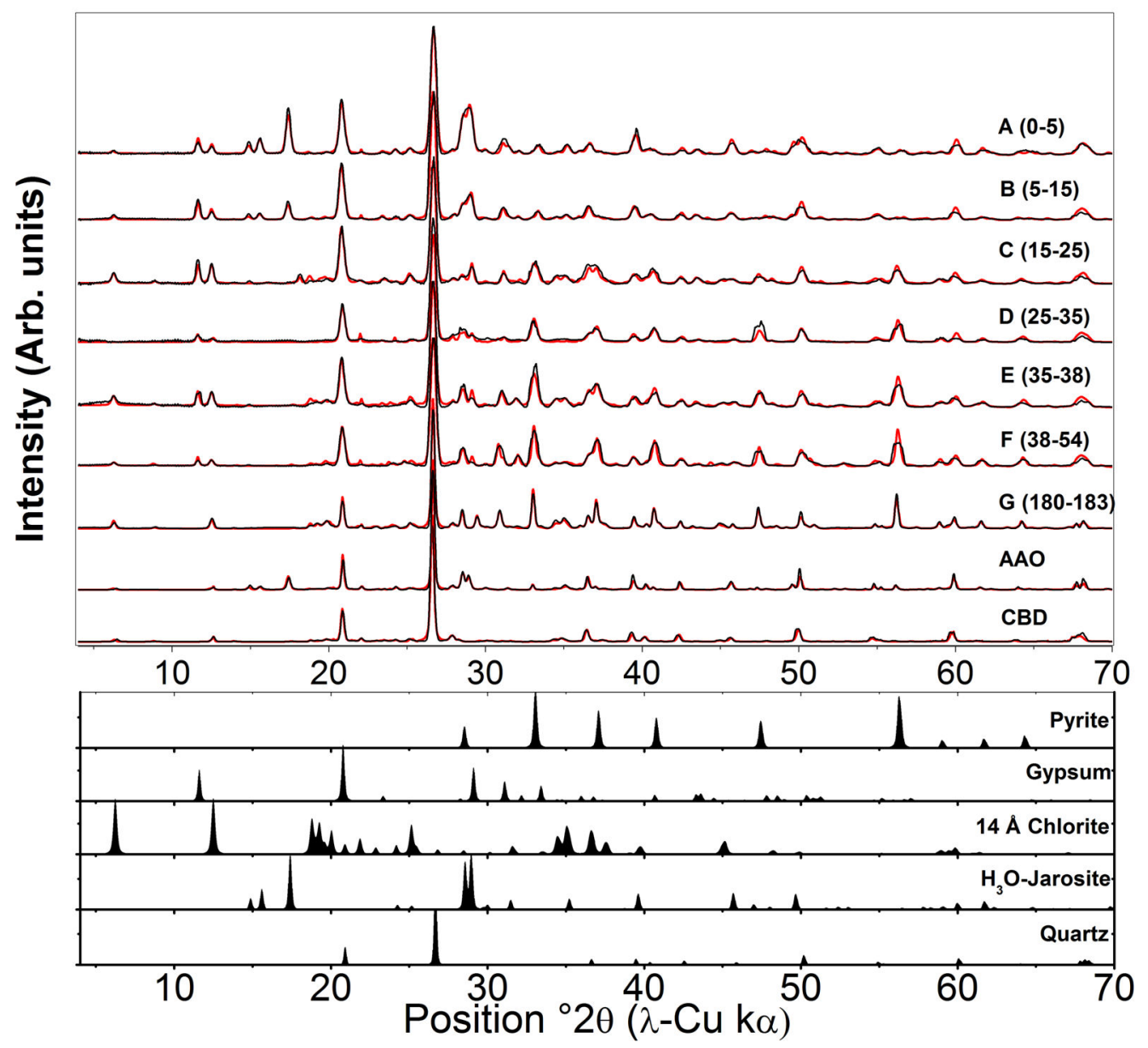

Figure 3.

X-ray diffraction data and fits. Synchrotron transmission XRD patterns (black lines) converted to $\mathrm{Cu} \mathrm{Ka}$ scale of IKMHSS pit samples at depths A-G and SSE samples, with corresponding Rietveld models (gray lines). Lower diffractograms represent the simulated patterns of selected phases used in the Rietveld models. Data are normalized to quartz. All jarosite group minerals (e.g., plumbojarosite, hydronium jarosite, jarosite) are modeled here using jarosite. Quantitative results are displayed in Table 4. 


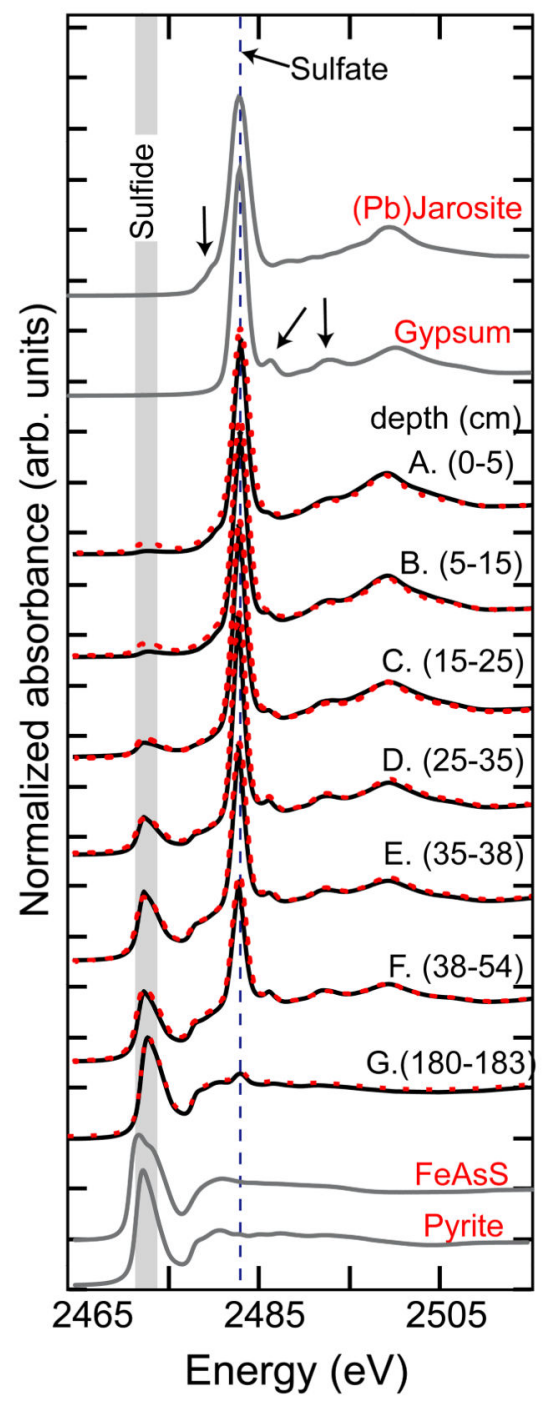

Figure 4.

Sulfur XANES. The S oxidation state was directly probed with S K-edge XANES (fits shown as dashed lines). Fits (range 2465-2515 eV) are tabulated in Table 5. Arrows indicate subtle sulfate features that differentiate gypsum and $(\mathrm{Pb})$ jarosite. 

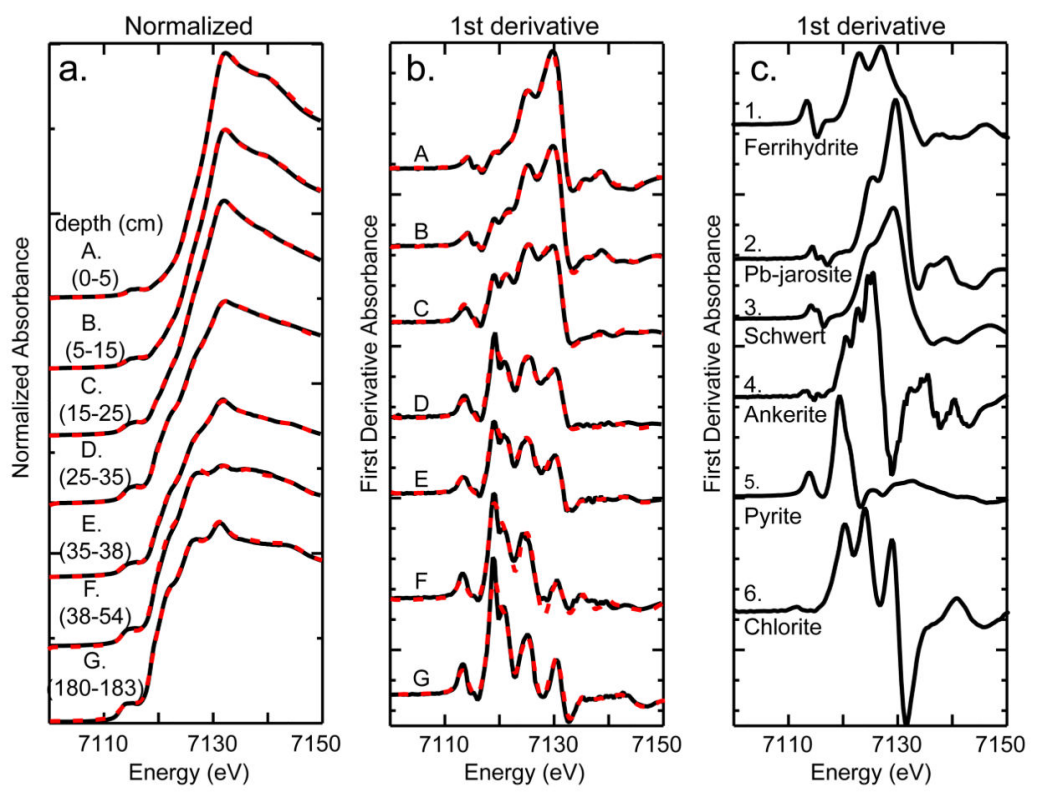

Figure 5.

Iron XANES. A) IKMHSS normalized XANES from the shallow pit $(0-55 \mathrm{~cm})$ and deeper core (to $180 \mathrm{~cm}$ ) from mine tailings (fits calculated from first-derivative fits shown in dashed lines), B) IKMHSS first derivative sample spectra (fits shown in dashed lines), and C) Fe first-derivative XANES of reference minerals used in XANES linear combination fits. The Fe XANES show a gradual transition from ferric oxide to ferrous sulfide phases from the surface to deep tailings. 


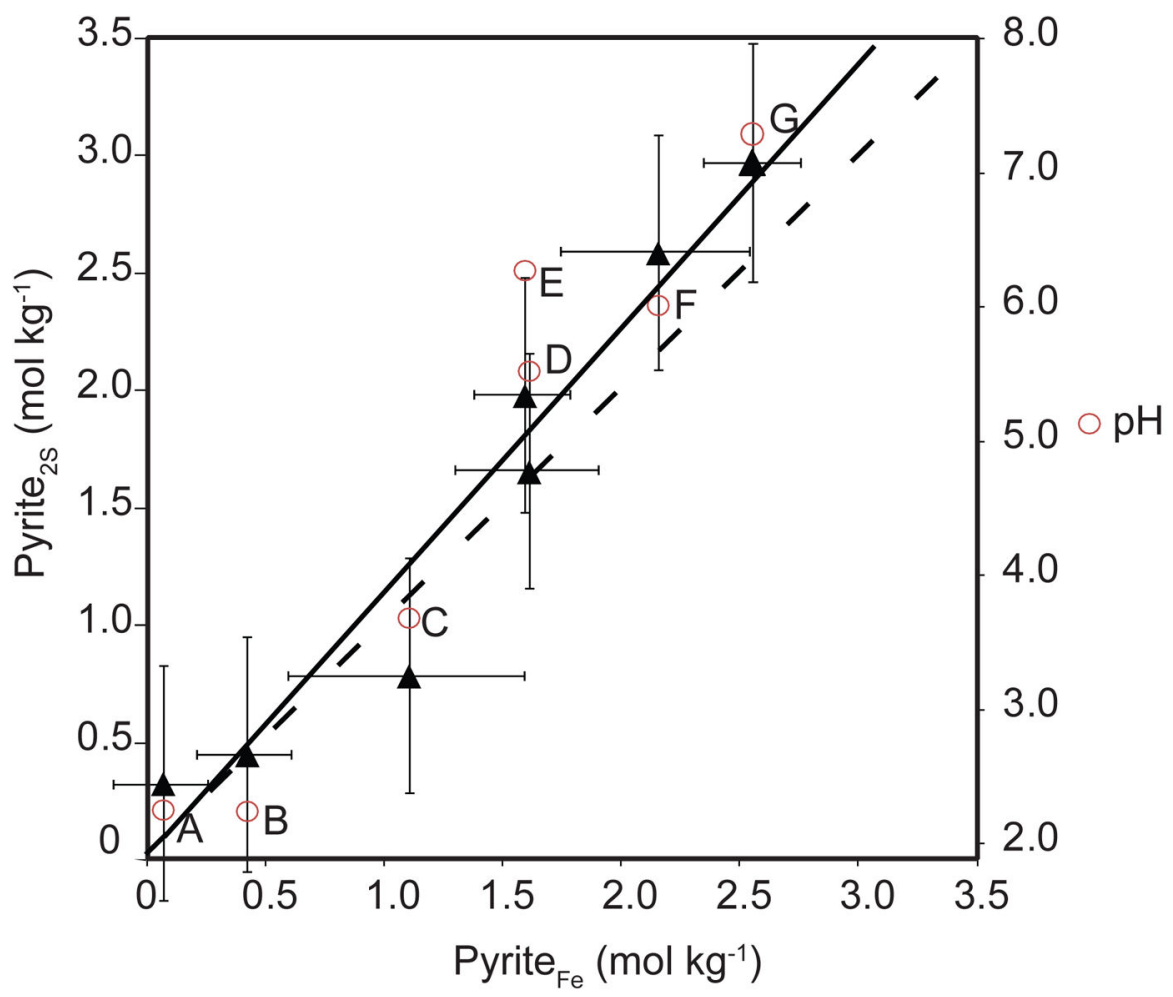

Figure 6.

Comparison of apparent pyrite concentration from linear combination fits to S XANES and Fe XANES. Moles of pyrite per kg of tailings were calculated from the pyrite fractional fit from Fe and $\mathrm{S} X A N E S$ spectra and the moles of Fe and $\mathrm{S}$ in the tailings respectively. The solid line is the linear correlation $\left(r^{2}=0.944\right)$, the dashed line is the Fe: $2 S$ line, accounting for stoichiometry of $\mathrm{FeS}_{2}$. Error bars are from the calculated error estimates from the $\mathrm{S}$ and Fe fits and not from replicate spectra. The $\mathrm{pH}$ is shown in circles for each associated sample. 


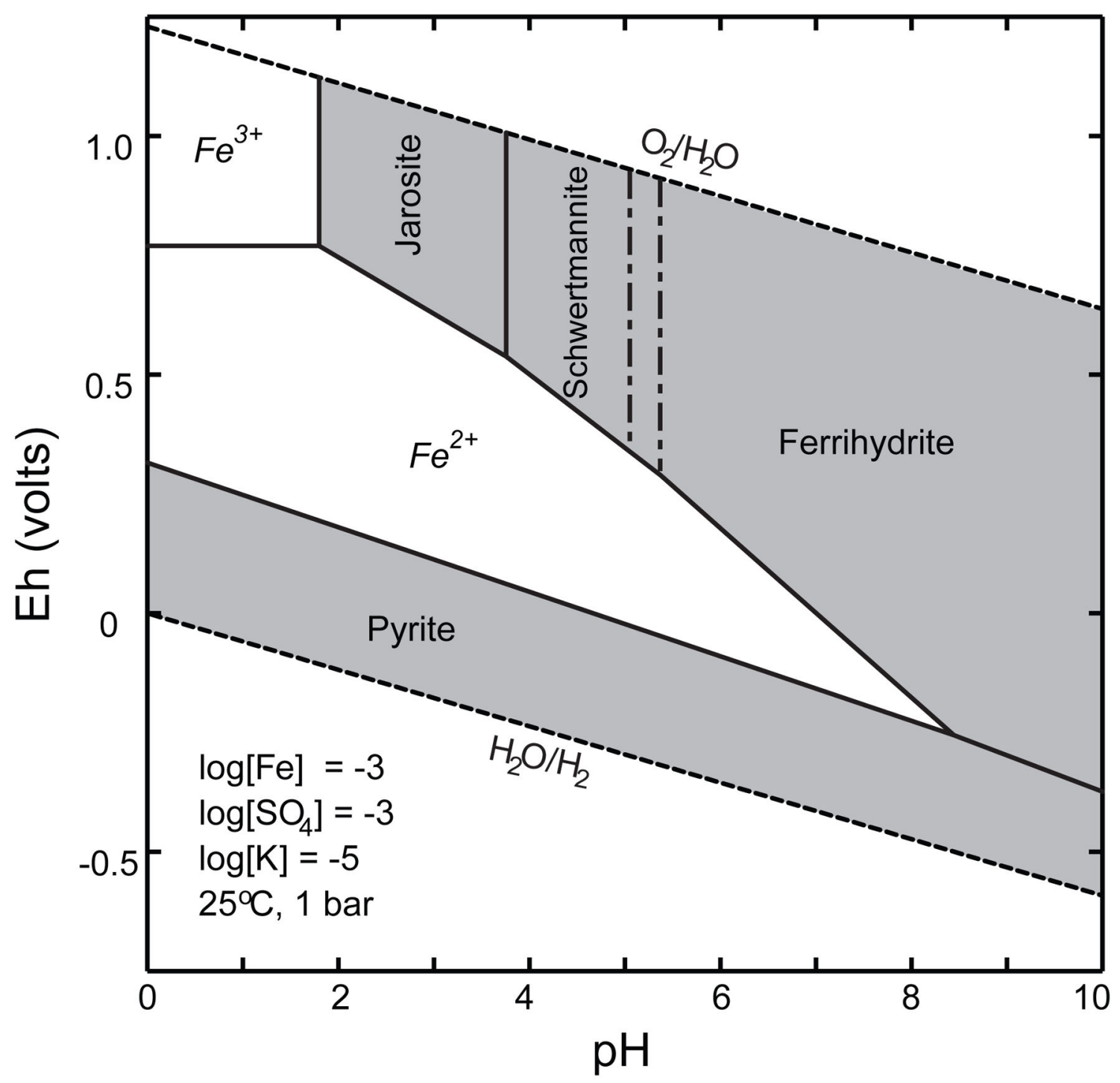

Figure 7.

Activity-activity diagrams, shown with the energetically favorable hematite and goethite suppressed to illustrate the metastable Fe and $\mathrm{S}$ phases. The Eh-pH diagram shows $\mathrm{Pb}-$ jarosite, schwertmannite and ferrihydrite as the meta-stable iron phases in oxicenvironments. The model was constrained by XANES and XRD, and elemental activities are given in inset. 


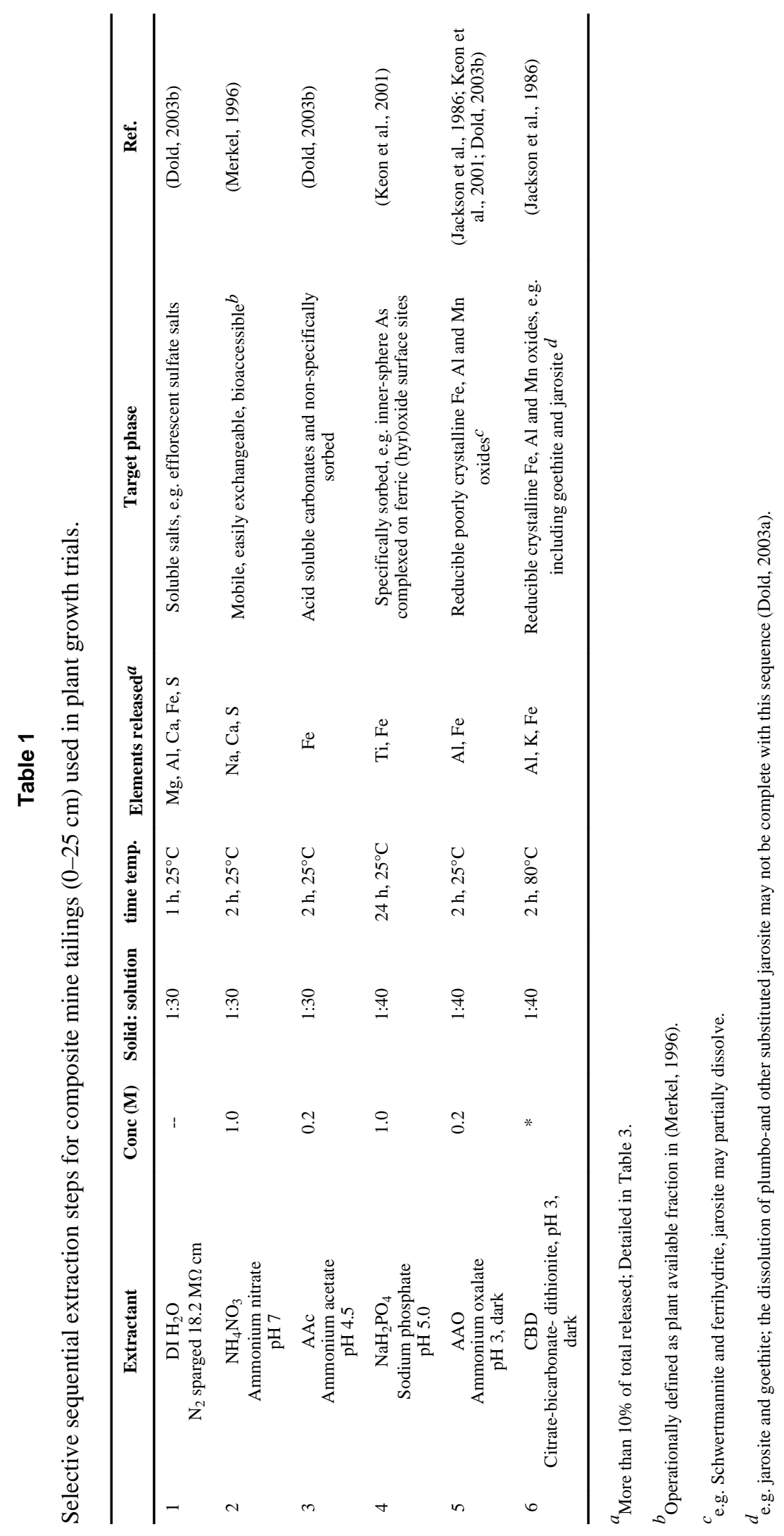




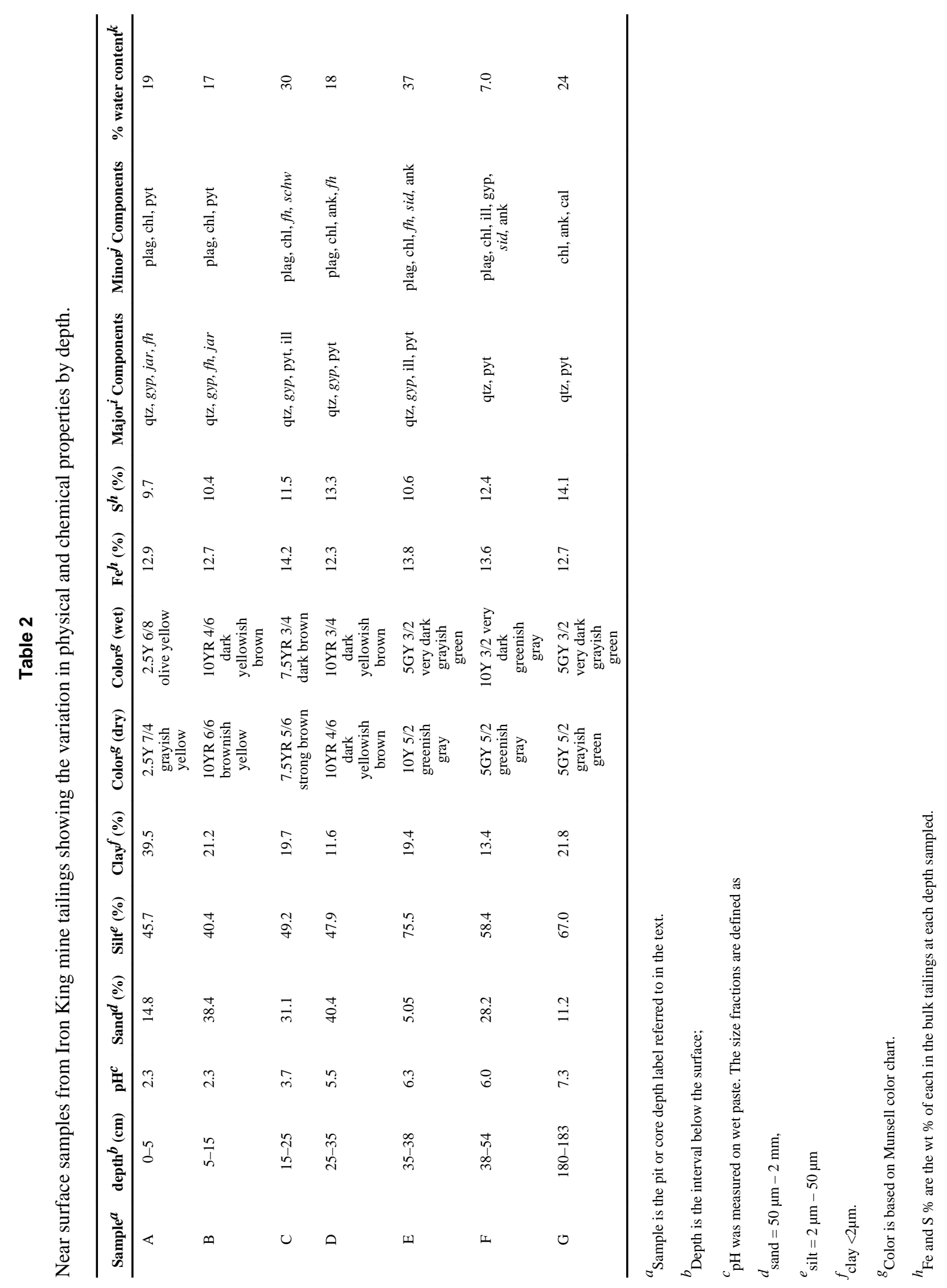




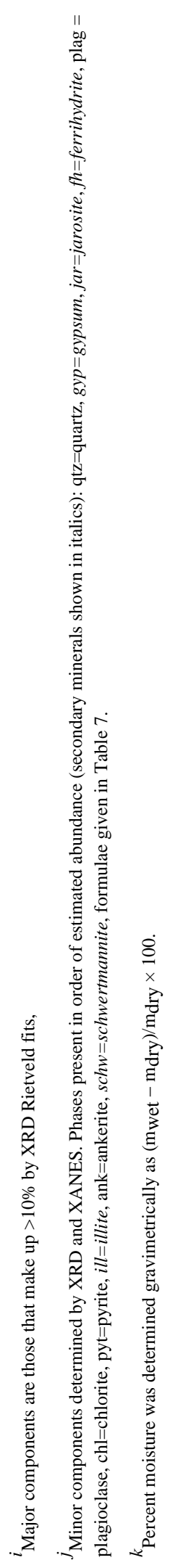




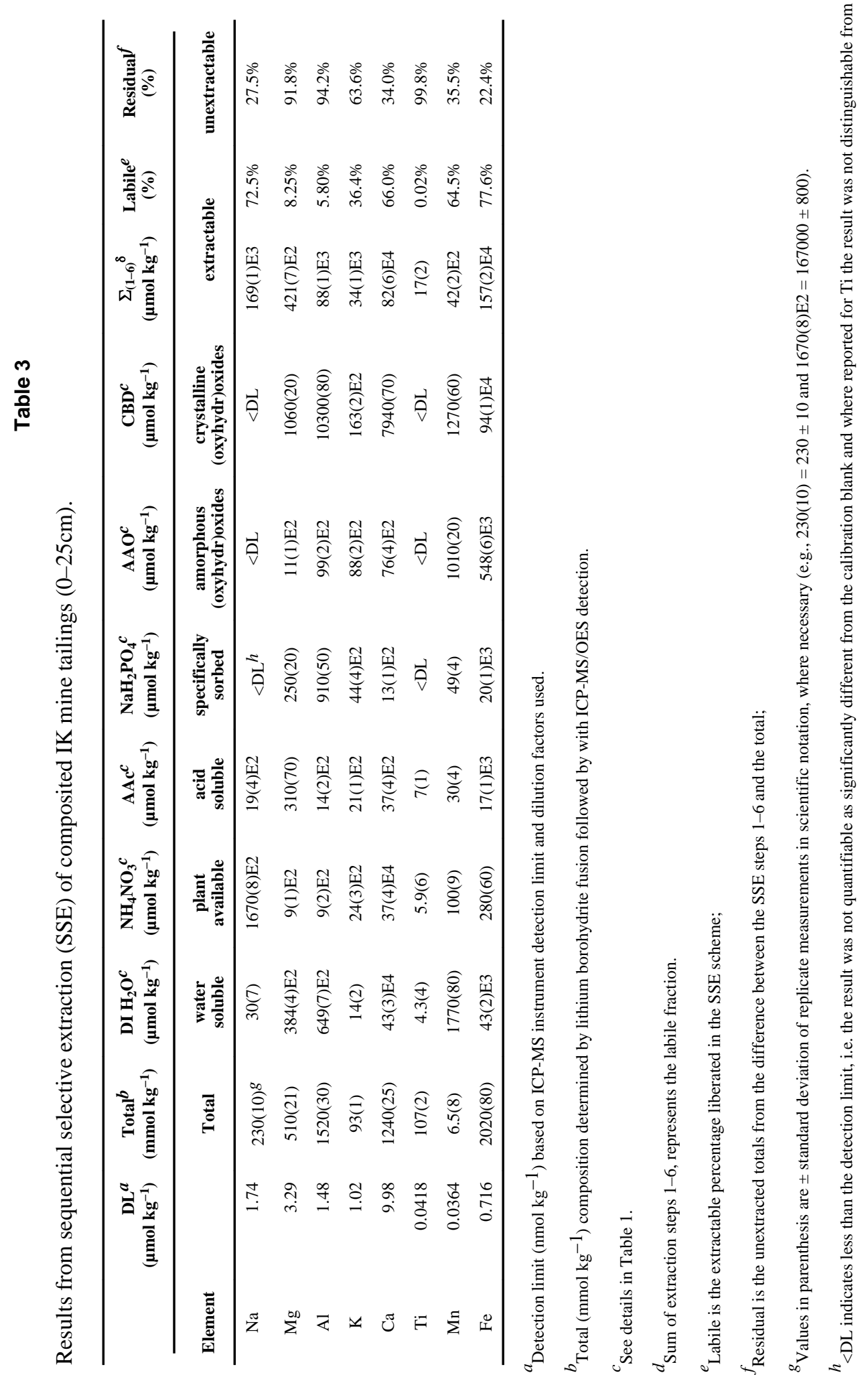




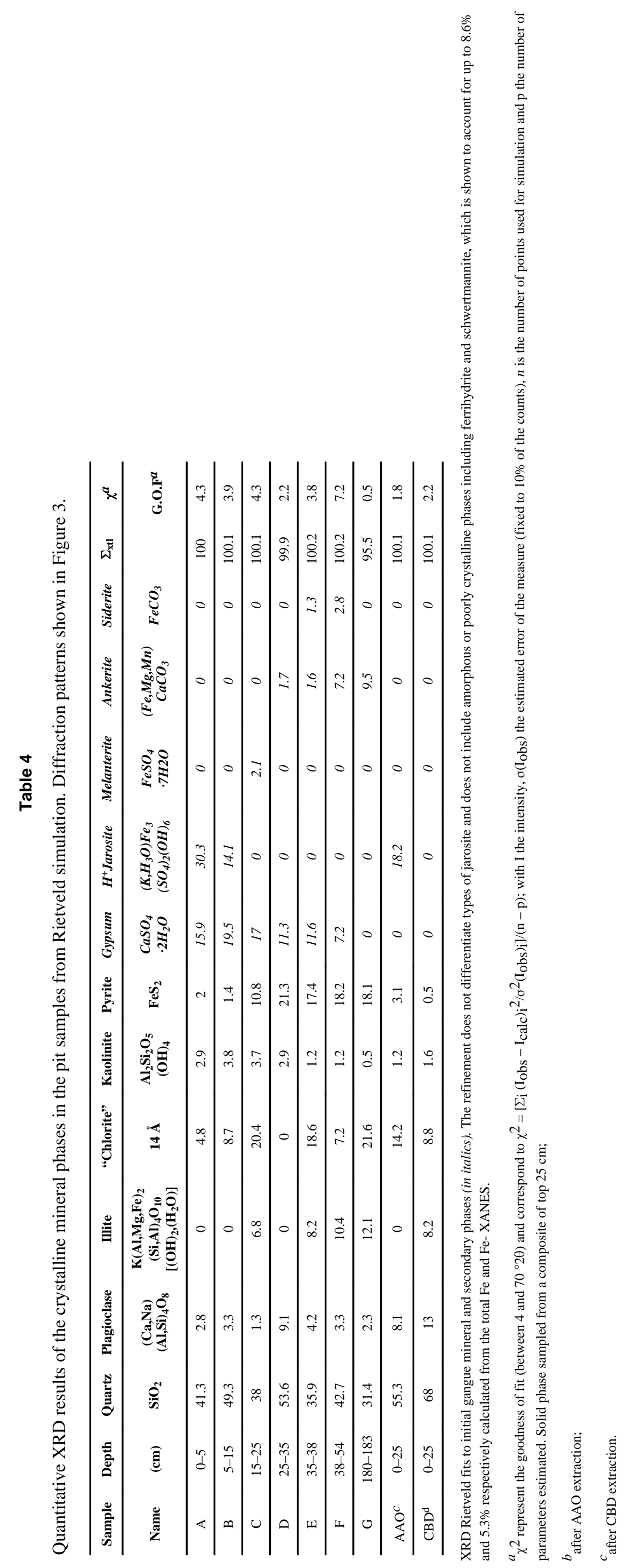




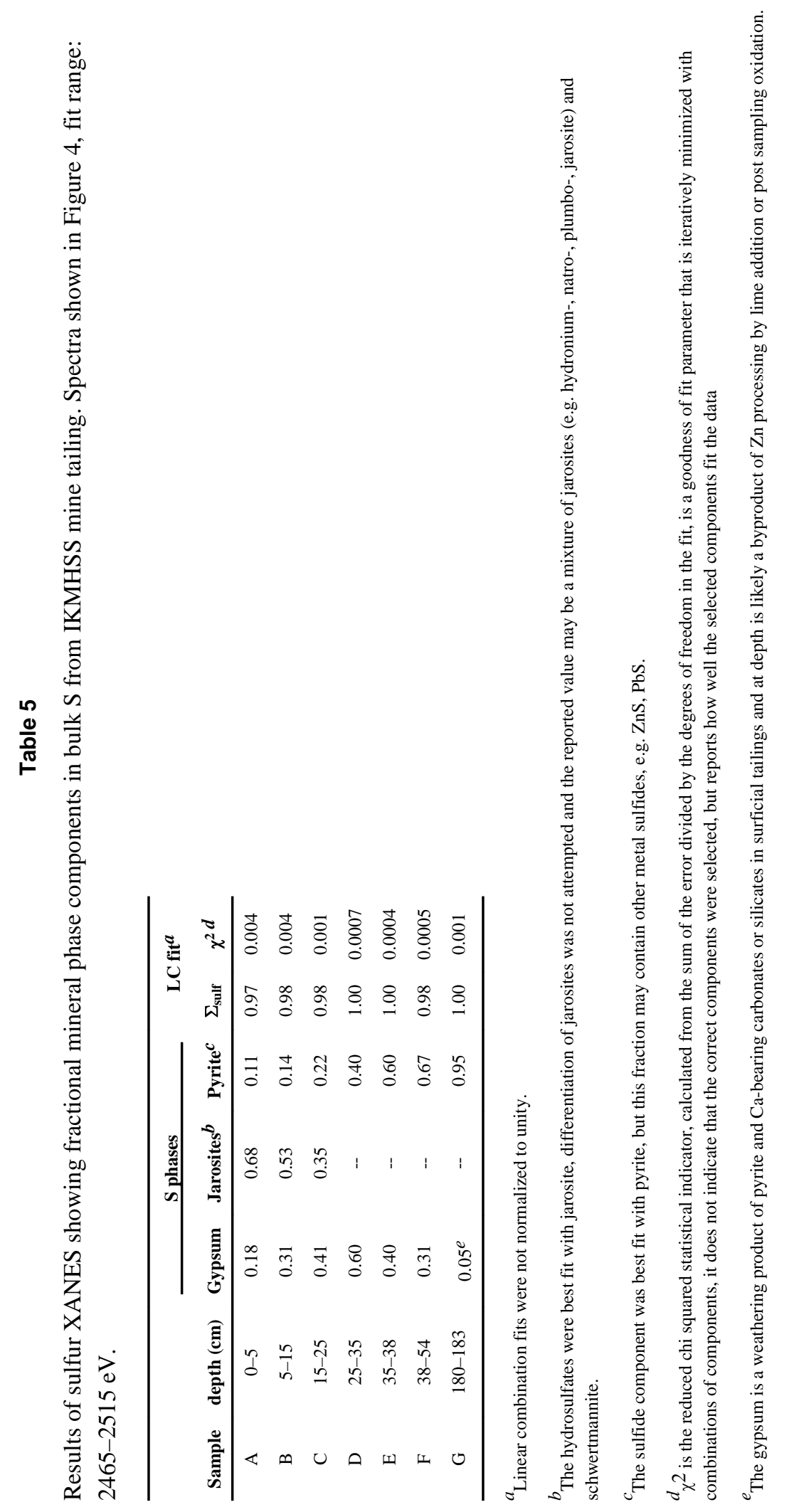




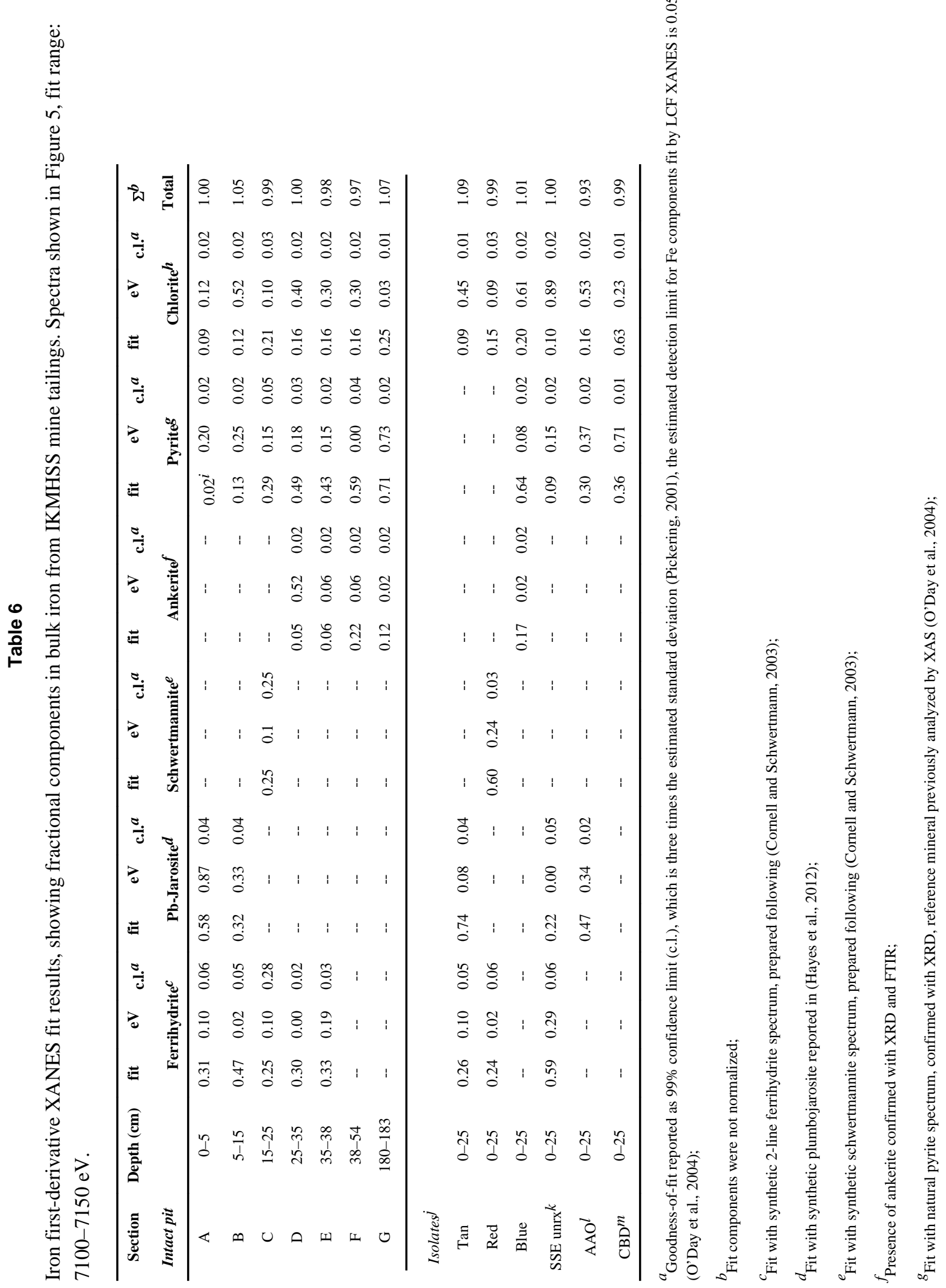


Hayes et al.

Page 34

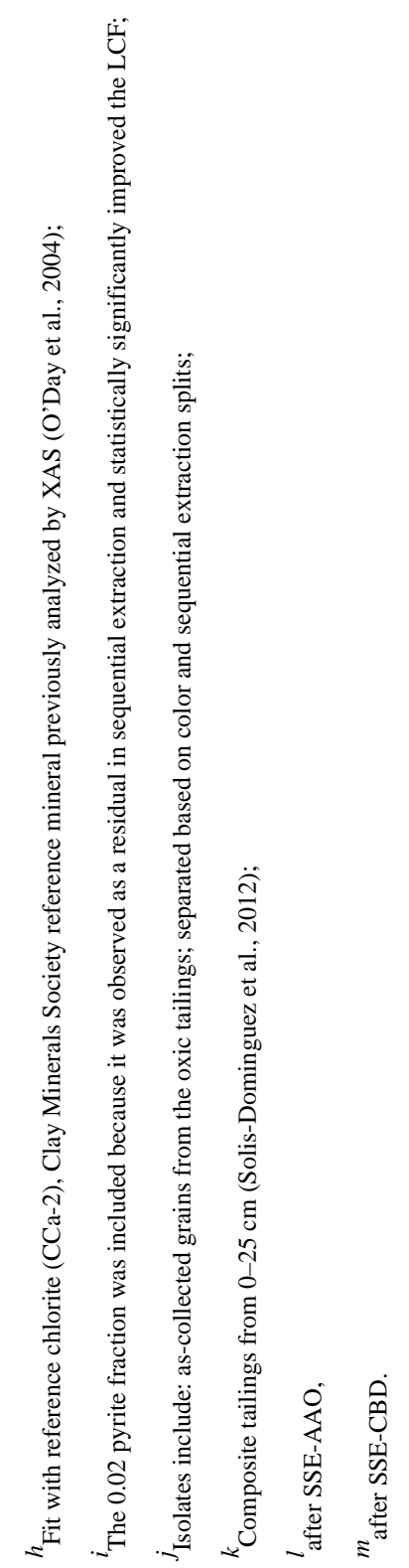




\section{Table 7}

Identification of mineral and amorphous phases in the Iron King mine tailings.

\begin{tabular}{|c|c|c|}
\hline Mineral $^{a}$ & Formulae & Detection $^{b}$ \\
\hline quartz & $\mathrm{SiO}_{2}$ & XRD \\
\hline plagioclase & $(\mathrm{Ca}, \mathrm{Na})(\mathrm{Al}, \mathrm{Si})_{4} \mathrm{O}_{8}$ & XRD \\
\hline illite & $\mathrm{K}(\mathrm{Al}, \mathrm{Mg}, \mathrm{Fe})_{2}(\mathrm{Si}, \mathrm{Al})_{4} \mathrm{O}_{10}\left[(\mathrm{OH})_{2}\left(\mathrm{H}_{2} \mathrm{O}\right)\right]$ & XRD \\
\hline chlorite & $(\mathrm{Mg}, \mathrm{Al}, \mathrm{Fe})_{6}(\mathrm{Si}, \mathrm{Al}, \mathrm{Fe})_{4} \mathrm{O}_{10}(\mathrm{OH})_{8}$ & XRD, Fe XANES \\
\hline kaolinite & $\mathrm{Al}_{2} \mathrm{Si}_{2} \mathrm{O}_{5}(\mathrm{OH})_{4}$ & XRD \\
\hline pyrite & $\mathrm{FeS}_{2}$ & XRD, Fe XANES, S XANES \\
\hline ankerite & $\mathrm{Ca}(\mathrm{Fe}, \mathrm{Mg}, \mathrm{Mn}) \mathrm{CO}_{3}$ & XRD, Fe XANES, FT-IR ${ }^{c}$ \\
\hline calcite & $\mathrm{CaCO}_{3}$ & XRD \\
\hline gypsum & $\mathrm{CaSO}_{4} \cdot 2 \mathrm{H}_{2} \mathrm{O}$ & XRD, S XANES \\
\hline jarosite & $\left(\mathrm{K}, \mathrm{H}_{3} \mathrm{O}\right) \mathrm{Fe}_{3}\left(\mathrm{SO}_{4}\right)_{2}(\mathrm{OH})_{6}$ & XRD, Fe XANES, S XANES \\
\hline melanterite & $\mathrm{FeSO}_{4} \cdot 7 \mathrm{H}_{2} \mathrm{O}$ & XRD \\
\hline siderite & $\mathrm{FeCO}_{3}$ & XRD \\
\hline schwertmannite & $\mathrm{Fe}_{8} \mathrm{O}_{8}(\mathrm{OH})_{6}\left(\mathrm{SO}_{4}\right)$ & Fe XANES \\
\hline ferrihydrite & $\left(\mathrm{Fe}_{2} \mathrm{O}_{3} * \mathrm{nH}_{2} \mathrm{O}\right)$ & Fe XANES \\
\hline plumbo-jarosite $^{d}$ & $(\mathrm{~Pb}) \mathrm{Fe}_{6}\left(\mathrm{SO}_{4}\right)_{4}(\mathrm{OH})_{12}$ & Fe XANES, XRD \\
\hline \multicolumn{3}{|c|}{$a_{\text {initial gangue minerals and secondary phases (in italics); }}$} \\
\hline \multicolumn{3}{|c|}{$b$ positive identification by any method was sufficient evidence for the presence of the phase, acknowledging the error in each technique; } \\
\hline
\end{tabular}

